\title{
LA DONACIÓN DE ÓVULOS EN LA REPRODUCCIÓN ASISTIDA: RIESGOS Y RESPONSABILIDAD
}

\author{
OVUM DONATION IN ASSISTED REPRODUCTION: RIKS \\ AND RESPONSABILITY
}

\author{
Belén AVILES ALEPUZ \\ Francisca RAMÓN FERNÁNDEZ
}

\section{Resumen}

El rápido desarrollo que han sufrido la biotecnología y biomedicina durante las últimas décadas y las numerosas líneas de investigación que su conocimiento ha permitido seguir, ha hecho posible el crecimiento de áreas de lo más diversas como es el caso de la reproducción asistida. El éxito de las técnicas de reproducción humana asistida actuales hace que cada vez sean más aquellos que deciden someterse a estos procedimientos con el anhelo de la paternidad y/o maternidad. Usuarias de estas técnicas como mujeres que sufran de fallo ovárico, óvulos de mala calidad o enfermedades hereditarias que no puedan ser detectadas optarán por técnicas de reproducción en las que se empleen óvulos de donantes, es por ello que la donación de óvulos es una práctica cada vez más común en nuestro país. El presente trabajo detalla el marco legislativo que abarca las técnicas de reproducción humana asistida profundizando en la situación de las donantes de óvulos, los riesgos que las mismas asumen perpetuando este acto y las responsabilidades, civil, administrativa o penal, en las que puede incurrir el profesional médico de los Centros autorizados al materializarse alguno de los riesgos asociados a la donación, ejemplificado con resoluciones actuales resueltas por los tribunales de nuestro país.

\footnotetext{
Abstract

The rapid development of biotechnology and biomedicine during the last decades and the numerous research lines that its knowledge has allowed to follow, has made possible the growth of the most diverse areas such as assisted reproduction. The success of current assisted human reproduction techniques means that more and more people decide to undergo these procedures with the yearning for fatherhood. Female users of these techniques such as women suffering from ovarian failure, poor oocyte quality or hereditary diseases that cannot be detected shall opt for reproductive techniques using donor oocytes, therefore oocyte donation is an increasingly common practice in our country. The present work details the legislative framework covering assisted human reproduction techniques by drilling down on the current situation of oocyte donors, the risks they assume by perpetuating this act and the responsibilities, civil, administrative or criminal responsibility, which may be committed by the medical practitioner of the authorized Centers when any of the risks associated with the donation materialize, exemplified by current judgements handed down by the courts of our country.
} 
Palabras clave

Extracción de ovocitos; Donantes; Óvulos; Ley; Responsabilidad jurídica; Riesgos de la extracción de ovocitos; Técnicas de reproducción humana asistida; Infertilidad; España

Keywords

Oocyte retrieval; Donors; Ovum; Law; Legal responsibilities; Oocyte retrieval risks; Assisted human reproduction techniques, Infertility, Spain.

\section{INTRODUCCIÓN}

Los hábitos de vida, la contaminación y diversas patologías son algunos de los factores que contribuyen al aumento de la tasa de infertilidad acaecido en las últimas décadas.

La infertilidad afecta a 34 millones de mujeres alrededor del mundo, siendo la quinta disfunción global más seria según la Organización Mundial de la Salud $(\mathrm{OMS})^{1}$. Este aumento de la infertilidad que afecta de forma igualitaria a hombres y mujeres sumado al anhelo de la paternidad y el continuo avance científico y tecnológico, especialmente en los campos de la biomedicina y la biotecnología, ha hecho posible un rápido e inesperado avance de las técnicas de reproducción humana asistida (TRHA).

En 1978 se dio a conocer universalmente con el nacimiento de Louise Brown en Reino Unido la primera "niña probeta". En nuestro país el primer nacimiento fruto de la misma TRHA, la Fecundación in vitro, no aconteció hasta seis años más tarde, en 1984.

El desarrollo de las TRHA como tratamiento para la esterilidad humana cuando otros métodos resultan poco adecuados o ineficaces abre expectativas y esperanzas para aquellos que sufren de esta disfunción a la vez que genera inquietud e incertidumbre social relativa a las posibilidades y consecuencias del

\footnotetext{
${ }^{1}$ WORLD HEALTH ORGANIZATION "WHO” (en español Organización Mundial de la Salud "OMS"), Infertility definitions and terminology. Disponible https://www. who.int/reproductivehealth/topics/infertility/definitions/en/ (Consultado el 10 de junio de 2019).
} 
IUS ET SCIENTIA (ISSN 244-8478) 2019, Vol. 5, nº 2, pp. 11-54 LA DONACIÓN DE ÓVULOS EN LA REPRODUCCIÓN ASISTIDA: RIESGOS Y RESPONSABILIDAD. Belén Avilés Alepuz y Francisca Ramón Fernández, Universidad Politécnica de Valencia, beaval@etsiamn.upv.es, frarafer@urb.upv.es Recibido: 17/09/2019. Aceptado: 10/10/2019 DOI: http://doi.org/10.12795/IESTSCIENTIA.2019.i02.03

uso de dichas técnicas. El investigador o profesional de la medicina que lleve a cabo estas técnicas dispone de óvulos y preembriones susceptibles de sufrir manipulación con distintos fines, entre ellos de investigación básica o experimental y de ingeniería genética, de ello deriva el temor e incertidumbre que envuelve dichas técnicas y que tiene alcance social, ético, biomédico y jurídico.

Por ello, con el fin de propiciar el inevitable y continuo progreso de la ciencia y tecnología, pero siempre priorizando el respeto a los derechos humanos y dignidad de los individuos, se aprueba la primera Ley sobre Técnicas de Reproducción Asistida, de 22 de noviembre de 1988. A lo largo de 31 años desde que fue aprobada la primera normativa ha habido una gran actividad legislativa con el fin de adaptar las regulaciones al continuo progreso de la investigación médica.

Sin embargo, una máxima que se mantiene en la cambiante legislación de dichas técnicas es la protección de las donantes de óvulos y la concepción del contrato de donación como un acuerdo gratuito, formal y secreto entre la donante y el Centro. Desde que se desarrollaron las primeras TRHA como tratamiento a parejas incapaces de concebir por los medios tradicionales, el perfil de las usuarias de dichas técnicas ha variado, siendo en la actualidad frecuente mujeres que optan por la maternidad diferida o mujeres sin pareja masculina entre las que se someten a dichos tratamientos. Un gran grupo entre las que se encuentran las parejas cuyo problema de fertilidad reside en la disfunción de los gametos femeninos o aquellas mujeres afectadas por enfermedades hereditarias optarán por una técnica en la que se empleen óvulos de donantes.

Es por ello que los óvulos de las donantes constituyen un bien muy preciado para los Centros autorizados, pues es material indispensable para la ejecución de estas técnicas cuya realización supone para el Centro un beneficio económico importante.

La donación de óvulos se ha presentado a la sociedad por los Centros como un acto con el que ayudar de forma anónima a mujeres que no pueden y desean concebir, indoloro, rápido y sin efectos secundarios. Sin embargo, dada la innegable dependencia de los Centros en las donantes y sus óvulos, cabe cuestionar la veracidad de dichas afirmaciones. 
IUS ET SCIENTIA (ISSN 244-8478) 2019, Vol. 5, nº 2, pp. 11-54 LA DONACIÓN DE ÓVULOS EN LA REPRODUCCIÓN ASISTIDA: RIESGOS Y RESPONSABILIDAD. Belén Avilés Alepuz y Francisca Ramón Fernández, Universidad Politécnica de Valencia, beaval@etsiamn.upv.es, frarafer@urb.upv.es Recibido: 17/09/2019. Aceptado: 10/10/2019 DOI: http://doi.org/10.12795/IESTSCIENTIA.2019.i02.03

El objetivo principal del presente trabajo es realizar un análisis en profundidad de la situación en la que se encuentran actualmente las mujeres que se someten a procedimientos de extracción de ovocitos con el fin de ser donados, dada la creciente demanda de las TRHA en la que se emplean dichos óvulos donados.

Con este fin, se realizará una revisión de la legislación actualmente vigente referente a las TRHA haciendo hincapié en los aspectos que atañen a las donantes y al contrato de donación.

De igual modo, el presente trabajo también pretende describir de manera resumida en qué consiste el procedimiento de extracción de gametos femeninos, así como las

consecuencias que los Centros les asocian, para posteriormente repasar en la literatura científica las complicaciones derivadas de este procedimiento percibidas por los profesionales, tanto a corto como a largo plazo, para que así el lector pueda formar su propia visión con respecto a si la salud de las donantes queda comprometida con este acto.

Por último, se expondrá un análisis detallando las responsabilidades jurídicas atribuibles a los profesionales cuando se materializa un daño derivado de alguna manera de la extracción de ovocitos, distinguiendo entre las distintas responsabilidades en las que se puede incurrir; civil, administrativa o penal. Serán mencionadas y descritas distintos recursos empleados como ejemplo de respuesta de la justicia española a estos supuestos.

Con nuestra propuesta, por tanto, se pretende que el lector logre mediante la lectura

del mismo comprender de forma simple en qué consiste la donación de óvulos, valorando la dificultad de determinar los riesgos asociados dado que la medicina no es una ciencia exacta, y las garantías que nos ofrece la legislación española. Todo ello buscando que el lector pueda formar una visión propia en cuanto a las virtudes e inconvenientes de la donación de óvulos como acto altruista.

\section{DONACIÓN DE ÓVULOS: ASPECTOS CLÍNICOS}

La donación de óvulos es, tal y como la describe la Comisión Nacional de 
IUS ET SCIENTIA (ISSN 244-8478) 2019, Vol. 5, nº 2, pp. 11-54 LA DONACIÓN DE ÓVULOS EN LA REPRODUCCIÓN ASISTIDA: RIESGOS Y RESPONSABILIDAD. Belén Avilés Alepuz y Francisca Ramón Fernández, Universidad Politécnica de Valencia, beaval@etsiamn.upv.es, frarafer@urb.upv.es Recibido: 17/09/2019. Aceptado: 10/10/2019 DOI: http://doi.org/10.12795/IESTSCIENTIA.2019.i02.03

Reproducción Humana Asistida $^{2}$, un acto altruista, voluntario y confidencial mediante el cual una mujer cede sus óvulos a otra mujer o pareja con el fin de ser utilizados para tratamientos de reproducción asistida cuando estén científica y clínicamente indicados.

Tradicionalmente se han empleado las técnicas de reproducción humana asistida (en adelante TRHA) con ovocitos de donantes para subsanar una muy baja reserva ovárica (RO) o mala calidad de los óvulos de las usuarias de estas TRHA que quisieran engendrar su propia descendencia. Gracias a los avances técnicos, acompañados de la correspondiente autorización por parte de la legislación, también se da actualmente la utilización de gametos de donantes en lugar de los propios en situaciones en las que exista riesgo de transmisión de algún defecto genético a la descendencia.

No obstante, la utilización de óvulos de donantes por causas de infertilidad femenina por alteraciones en la RO sigue siendo la más frecuente. La RO se define como el número y la calidad de los folículos que quedan en el ovario en un momento determinado, aunque existen diferentes hormonas empleadas como biomarcadores para la cuantificación relativa de estos, la forma de cuantificación de la RO más generalizada es mediante la medición de la hormona antimülleriana $(\mathrm{AMH}){ }^{3}$

Las principales funciones de la AMH son: a) la diferenciación sexual del embrión masculino por la síntesis de $\mathrm{AMH}$ en los testículos, lo que lleva a la pérdida del conducto de Müller; b) en el ovario, el AMH se expresa en las células de la granulosa de los folículos primordiales en crecimiento. La AMH deja de expresarse en aquellos folículos que hayan alcanzado el tamaño y estadio de diferenciación tal, que serán seleccionados para ser el folículo dominante del cual surgirá el óvulo por acción de la hormona estimulante de los folículos (FSH). ${ }^{4} \mathrm{La}$

${ }^{2}$ COMISIÓN NACIONAL DE REPRODUCCIÓN HUMANA ASISTIDA, Aspectos clínicos específicos de los donantes de ovocitos. Disponible en: http://www.cnrha.mscbs.gob.es/registros/donantes/aspectosClinicos/ovocitos/home.htm

(Consultado el 23 de mayo de 2019).

3 APARICIO RODRÍGUEZ, I., Papel de la hormona anti-mülleriana en el manejo de la reserva ovárica en reproducción asistida, Tesis doctoral, ORDÁS SANTO TOMÁS, J. y CUADRADO MANGAS, M. C. (dir.), Universidad Autónoma de Madrid. Madrid, 2009. Disponible en: https://repositorio.uam.es/bitstream/handle/10486/748/20275_aparicio_rodriguez_iria.pdf?sequenc $\mathrm{e}=1$ \&isAllowed $=\mathrm{y}$ (Consultado el 26 de julio de 2019).

4 KWEE J., BROEKMANS F.J., HENDRIKS D.J., MOL, B.W. y LAMBALK, C.B., “A 
IUS ET SCIENTIA (ISSN 244-8478) 2019, Vol. 5, nº 2, pp. 11-54 LA DONACIÓN DE ÓVULOS EN LA REPRODUCCIÓN ASISTIDA: RIESGOS Y RESPONSABILIDAD. Belén Avilés Alepuz y Francisca Ramón Fernández, Universidad Politécnica de Valencia, beaval@etsiamn.upv.es, frarafer@urb.upv.es Recibido: 17/09/2019. Aceptado: 10/10/2019 DOI: http://doi.org/10.12795/IESTSCIENTIA.2019.i02.03

AMH actúa inhibiendo una producción excesiva de folículos durante el ciclo ovulatorio, el cual llevaría al agotamiento prematuro del pool folicular. ${ }^{5}$

Otro aspecto de la RO es la calidad del ovocito liberado del folículo dominante durante la ovulación, el cual se valora como la probabilidad de embarazo en tratamientos de infertilidad como la Fecundación in vitro (FIV). ${ }^{6}$

Hay numerosas razones por las que una mujer puede presentar una baja RO, la insuficiencia ovárica prematura es la pérdida de la función ovárica antes de los 40 años de edad la cual se ha visto relacionada con causas iatrogénicas, genéticas, metabólicas, autoinmunes y ambientales, con una incidencia de 1 cada 100 mujeres menores de 40 años. $^{7}$ No obstante, se sabe que la edad es uno de los principales determinantes en el aumento de la incidencia de la esterilidad en general $^{8}, \mathrm{y}$ disminución de la reserva ovárica en particular y, dado que la edad media en la que se tiene el primer hijo en nuestro país ha aumentado progresivamente en las últimas décadas ${ }^{9}$, esto explica la creciente demanda de las TRHA y de la disponibilidad de óvulos. ${ }^{10}$

En cuanto al procedimiento para donar ovocitos, en España se realiza en los

systematic review of tests predicting ovarian reserve and IVF outcome". Human Reproduction Update, 12(6), 2006, pp. 685-718. Disponible en: https://pdfs.semanticscholar.org/a1f0/e8629371e9b60bfd67fce4e791dc8dea50cf.pdf? ga=2.16355 0716.135265663.1564251597-898571686.1562517395 (Consultado el 24 de julio de 2019).

${ }^{5}$ APARICIO RODRÍGUEZ, I., Papel de la hormona anti-mülleriana en el manejo de la reserva ovárica en reproducción asistida, cit., p. 21.

${ }^{6}$ APARICIO RODRÍGUEZ, I., Papel de la hormona anti-mülleriana en el manejo de la reserva ovárica en reproducción asistida, cit., p. 29. Cfr. BROEKMANS, F. J., VISSER, J. A., LAVEN, J. S., BROER, S. L., THEMMEN, A. P., y FAUSER, B. C., "Anti-Müllerian hormone and ovarian dysfunction”. Trends in Endocrinology \& Metabolism, 19(9), 2008, pp. 340-347.

7 JUÁREZ, K., LARA, R. y GARCÍA, J., "Insuficiencia ovárica prematura: una revisión”, Revista chilena de obstetricia y ginecología, 77(2), 2012, pp.148-153. Disponible en: https://scielo.conicyt.cl/pdf/rchog/v77n2/art12.pdf (Consultado el 26 de julio de 2019).

${ }^{8}$ WALLACE, W.H.B. y KELSEY, T.W., "Human Ovarian Reserve from Conception to the Menopause", PLoS ONE 5(1): e8772, 2010. Disponible en: https://www.researchgate.net/publication/41174979_Human_Ovarian_Reserve_from_Conception_ to_the_Menopause (Consultado el 27 de julio de 2019).

9 OFICINA EUROPEA DE ESTADÍSTICA EUROSTAT, Evolución de la edad media al primer hijo 1981-2013 en España. Disponible en: https://ec.europa.eu/eurostat/statisticsexplained/index.php?title=File:Evolución_de_la_edad_media_al_primer_hijo_1981-

2013_en_España.png (Consultado el 10 de mayo de 2019).

10 ROBLES CORCHADO, A., Ensayo clínico, prospectivo, aleatorizado y comparativo, para determinar la eficacia y seguridad de dos protocolos para hiperestimulación ovárica controlada en mujeres que van a ser tratadas con inseminación artificial y que han sido diagnosticadas de esterilidad de origen desconocido, Tesis doctoral, CARRERAS COLLADO, R., y CHECA VIZCAINO, M. A. (dir.), Universidad Autónoma de Barcelona, Barcelona, 2014. Disponible en: https://ddd.uab.cat/pub/tesis/2014/hdl_10803_283948/arc1de1.pdf (Consultado el 27 de julio de 2019). 
IUS ET SCIENTIA (ISSN 244-8478) 2019, Vol. 5, nº 2, pp. 11-54 LA DONACIÓN DE ÓVULOS EN LA REPRODUCCIÓN ASISTIDA: RIESGOS Y RESPONSABILIDAD. Belén Avilés Alepuz y Francisca Ramón Fernández, Universidad Politécnica de Valencia, beaval@etsiamn.upv.es, frarafer@urb.upv.es Recibido: 17/09/2019. Aceptado: 10/10/2019 DOI: http://doi.org/10.12795/IESTSCIENTIA.2019.i02.03

centros de reproducción públicos o privados autorizados para ello en los cuales las futuras donantes recibirán información exhaustiva tanto del procedimiento como de los posibles efectos secundarios.

El primer paso consiste en una entrevista en la que se evalúa el estado psicofísico de la futura donante con el fin de recoger datos clínicos relevantes que determinen si es o no idónea para la donación de óvulos, un 22,82\% de las candidatas a donar óvulos serán rechazadas por distintos motivos tras la evaluación psicológica. ${ }^{11}$

Si la futura donante cumple con los requisitos de selección, el centro planificará la donación de óvulos la cual consta de tres fases: tratamiento hormonal, punción ovárica y seguimiento posterior.

\section{Legislación aplicable a las técnicas de reproducción humana asistida}

La Fecundación In Vitro (FIV) con Transferencia de Embriones (TE) se dio a conocer universalmente en 1978 con el nacimiento de Louise Brown en Reino Unido. En nuestra nación, el primer niño nacido con esta misma técnica tuvo lugar seis años más tarde, en 1984. Esto fue posible gracias a una serie de avances y descubrimientos científicos y tecnológicos, principalmente biomédicos y biotecnológicos, en el ámbito de las técnicas de reproducción alternativas para la esterilidad humana.

Tales avances acompañaron, como no puede ser de otra forma, una serie de incertidumbres y temores con alcance social, ético, biomédico y jurídico. Es por ello que en 1988 se promulga la Ley 35/1988, de 22 de noviembre, sobre Técnicas de Reproducción Asistida ${ }^{12}$ (Ley 35/1988).

Con esta primera ley quedaban reguladas las técnicas de reproducción alternativas a la esterilidad de la pareja humana, en virtud de la Ley 35/1988; a) Inseminación artificial (IA), con semen del marido o varón de la pareja (IAC) o con semen procedente de un donante (IAD), también conocido como técnicas homólogas y heterólogas, respectivamente; b) Fecundación in vitro (FIV); c) Transferencia

\footnotetext{
${ }^{11}$ LUCÍA, C., y NÚÑEZ, R., "Revisión del perfil sociodemográfico de una muestra local de donantes de gametos, en España: motivación para la donación, procedencia de los donantes, ocupación”, Medicina Reproductiva y Embriología Clínica, 2(1), 2015, pp. 23-30.

${ }^{12}$ BOE número 35, de 22 de noviembre de 1988.
} 
IUS ET SCIENTIA (ISSN 244-8478) 2019, Vol. 5, nº 2, pp. 11-54 LA DONACIÓN DE ÓVULOS EN LA REPRODUCCIÓN ASISTIDA: RIESGOS Y RESPONSABILIDAD. Belén Avilés Alepuz y Francisca Ramón Fernández, Universidad Politécnica de Valencia, beaval@etsiamn.upv.es, frarafer@urb.upv.es Recibido: 17/09/2019. Aceptado: 10/10/2019 DOI: http://doi.org/10.12795/IESTSCIENTIA.2019.i02.03

intratubárica de gametos (TIG). Esta Ley autorizaba la investigación sobre los preembriones exclusivamente si tenían por objeto el bienestar del nasciturus y el favorecimiento de su desarrollo, a la vez que limitaba la investigación con gametos a la mejora de las técnicas de obtención, maduración y crioconservación de los mismos.

El paso del tiempo y la evolución en la utilización y aplicación de las TRHA pusieron de manifiesto las limitaciones de la Ley 35/1988 e hicieron necesaria la aprobación de una nueva regulación adaptada a la realidad actual. Con este fin, entró en vigor la Ley 14/2006, de 26 de mayo, sobre técnicas de reproducción humana asistida ${ }^{13}$, todavía vigente en la actualidad (Ley 14/2006).

La Ley 14/2006 Artículo 1.2 define preembrión como “el embrión in vitro constituido por el grupo de células resultantes de la división progresiva del ovocito desde que es fecundado hasta 14 días más tarde" y tiene por objeto: a) regular la aplicación de las técnicas de reproducción humana asistida acreditadas científicamente y clínicamente indicadas; b) regular la aplicación de las técnicas de reproducción humana asistida en la prevención y tratamiento de enfermedades de origen genético, siempre que existan las garantías diagnósticas y terapéuticas suficientes y sean debidamente autorizadas; c) regular los supuestos y requisitos de utilización de gametos y preembriones humanos crioconservados. ${ }^{14}$

En cuanto a la utilización de gametos y preembriones humanos crioconservados, el Artículo 11.4 prevé cuatro diferentes destinos posibles.

Cabe destacar por su relevancia, la apertura legislativa del uso de la Ley 14/2006 a otras competencias distintas al de la solución de los problemas de esterilidad. Particularmente, para evitar la aparición de enfermedades en las personas nacidas que carecen de tratamiento curativo realizando el llamado diagnóstico genético preimplantacional, cuya regulación y autorización queda recogido en al Artículo 12 de la Ley 14/2006.

\footnotetext{
${ }^{13}$ BOE número 14, de 26 de mayo de 2006.

14 RUIZ SÁENZ, A., "El contrato de donación de gametos y preembriones en la legislación española sobre técnicas de reproducción humana asistida", Cuadernos Ibero-Americanos de Derecho Sanitario, 2(2), 2013, pp. 786-801. Disponible en: https://www.researchgate.net/publication/290147543_El_contrato_de_donacion_de_gametos_y_pr eembriones_en_la_legislacion_espanola_sobre_tecnicas_de_reproduccion_humana_asistida (Consultado el 26 de julio de 2019).
} 
IUS ET SCIENTIA (ISSN 244-8478) 2019, Vol. 5, nº 2, pp. 11-54 LA DONACIÓN DE ÓVULOS EN LA REPRODUCCIÓN ASISTIDA: RIESGOS Y RESPONSABILIDAD. Belén Avilés Alepuz y Francisca Ramón Fernández, Universidad Politécnica de Valencia, beaval@etsiamn.upv.es, frarafer@urb.upv.es Recibido: 17/09/2019. Aceptado: 10/10/2019 DOI: http://doi.org/10.12795/IESTSCIENTIA.2019.i02.03

\section{Donantes y contratos de donación en la Le 14/2006, sobre técnicas de reproducción humana asistida}

Los donantes y contratos de donación están regulados por el Artículo 5 de la Ley 14/2006. Los requisitos de los donantes, de gametos y preembriones, son tener más de 18 años, buen estado de salud psicofísica y plena capacidad de obrar. Con el fin de evaluar el estado psicofísico de los donantes, estos deben de haber superado un protocolo de carácter obligatorio que determine sus características fenotípicas y psicológicas y las pruebas analíticas necesarias que determinen que no padecen enfermedades genéticas, hereditarias o infecciosas transmisibles a la descendencia.

Con objeto de lograr una uniformidad en criterios básicos mínimos a los que deberá someterse a los donantes y facilitar la labor de los equipos biomédicos, entra en vigor el Real Decreto 412/1996, de 1 de marzo (Real Decreto 412/1996), por el que se establecen los protocolos obligatorios de estudio de los donantes y usuarios relacionados con las técnicas de reproducción humana asistida y se regula la creación y organización del Registro Nacional de Donantes de Gametos y Preembriones con fines de reproducción humana. Los estudios mínimos a realizar por los centros a los posibles donantes son, de acuerdo con el Artículo 4, los siguientes: grupo sanguíneo; factor Rh; VDRL o prueba similar para detectar la sífilis; screening de hepatitis; test de detección de marcadores de VIH; estudio clínico para la detección de fases clínicas infectivas de toxoplasmosis, rubeola, herpes virus y citomegalo virus; y estudio para la detección de neisseria gonorrhoeae y chlamydia trachomatis.

La donación de gametos, para las finalidades previstas por la Ley 14/2006 anteriormente citadas, se entiende en todo caso por la ley como un acto anónimo, gratuito, formal y confidencial entre el donante y el centro, razón por la cual se prohíbe expresamente el carácter lucrativo o comercial de dicho acto. Si bien es cierto que se prevé una compensación económica por el acto de la donación, siendo actualmente en el caso de los gametos femeninos entre 600 y 1.000 $\operatorname{euros}^{15}$, este es fijado periódicamente por el Ministerio de Sanidad, Consumo y

${ }^{15}$ GARCÍA, E. (2013). "El «negocio» de donar óvulos y semen”, Levante-EMV, 10 de junio de 
IUS ET SCIENTIA (ISSN 244-8478) 2019, Vol. 5, nº 2, pp. 11-54 LA DONACIÓN DE ÓVULOS EN LA REPRODUCCIÓN ASISTIDA: RIESGOS Y RESPONSABILIDAD. Belén Avilés Alepuz y Francisca Ramón Fernández, Universidad Politécnica de Valencia, beaval@etsiamn.upv.es, frarafer@urb.upv.es Recibido: 17/09/2019. Aceptado: 10/10/2019 DOI: http://doi.org/10.12795/IESTSCIENTIA.2019.i02.03

Bienestar Social previo informe de la Comisión Nacional de Reproducción Humana Asistida con el fin de compensar estrictamente las molestias físicas y los gastos de desplazamiento y laborales derivados de la donación, nunca como incentivo económico en virtud del Artículo 5.3.

Antes de llevar a cabo el procedimiento de donación, el centro ha de obtener el consentimiento informado por escrito de los donantes. Para ello, el centro debe informar de los fines y consecuencias del acto de la donación de una forma comprensible para el donante, la información y asesoramiento sobre las técnicas empleadas se extenderá a los aspectos biológicos, jurídicos y éticos de aquellas, debiendo precisar igualmente la información relativa a las condiciones económicas en virtud del Artículo 5.4.

La donación será revocable únicamente en el caso de que el donante requiera los gametos para su uso personal y estos se encuentren disponibles. Además, la revocación de la donación conlleva por parte de la donante la devolución de los gastos al centro médico (Artículo 5.2).

Por último, la Ley 14/2006 Artículo 5.7 limita a seis el número máximo de hijos nacidos en España generados con gametos de un mismo donante. Con el fin de regular este límite, la ley establece que el donante debe declarar en cada donación si ha realizado otras previas, así como las condiciones de éstas, el momento y el centro en que se hubiera realizado. Esta ley hace responsable al centro, en el mismo Artículo 5.7, de comprobar de manera fehaciente la identidad de los donantes, así como las consecuencias de las donaciones anteriores en cuanto a los hijos nacidos previamente si los hubiese y el número de estos. Para facilitar esta labor, el Gobierno mediante real decreto regulará la organización y funcionamiento del registro nacional de donantes, tal como se establece en el Artículo 21 de la Ley 14/2006.

\section{RIESGOS ASOCIADOS A LA EXTRACCIÓN DE OVOCITOS}

Con el fin de comprender los riesgos derivados del procedimiento de extracción 
IUS ET SCIENTIA (ISSN 244-8478) 2019, Vol. 5, nº 2, pp. 11-54 LA DONACIÓN DE ÓVULOS EN LA REPRODUCCIÓN ASISTIDA: RIESGOS Y RESPONSABILIDAD. Belén Avilés Alepuz y Francisca Ramón Fernández, Universidad Politécnica de Valencia, beaval@etsiamn.upv.es, frarafer@urb.upv.es Recibido: 17/09/2019. Aceptado: 10/10/2019 DOI: http://doi.org/10.12795/IESTSCIENTIA.2019.i02.03

de ovocitos a los que las donantes se exponen, se desarrollará en primer lugar el proceso clínico de extracción de ovocitos que consta de tres fases de acuerdo con la Comisión Nacional de Reproducción Humana Asistida: tratamiento hormonal, punción ovárica y seguimiento posterior.

Cabe recordar, que estos riesgos no son exclusivos de las donantes de óvulos, sino que se aplican a cualquier mujer que se someta a un procedimiento de extracción de ovocitos, como las mujeres usuarias de TRHA en procedimientos que empleen óvulos propios. ${ }^{16}$

Tratamiento hormonal: El tratamiento hormonal responde a la necesidad de estimular el ovario con el fin de favorecer la maduración y posterior extracción de más de un ovocito por ciclo reproductivo con el fin de rentabilizar económica y clínicamente el procedimiento de obtención de óvulos.

El primer paso es el de frenado hipofisiario con el que se busca inhibir la síntesis de gonadotropinas propias de la hipófisis que pudieran interferir con el posterior proceso de estimulación, permitiendo controlar los tiempos y plazos de la ovulación con mayor precisión. ${ }^{17}$

Existen actualmente dos protocolos en uso, uno mediante la aplicación de agonistas de la hormona liberadora de gonadotropinas (agonistas-GnRh) y otro mediante antagonistas de la hormona liberadora de gonadotropinas (antagonistasGnRh).

El protocolo de control de la estimulación ovárica más comúnmente empleado en el procedimiento de FIV es mediante la administración de agonistas-GnRh. La sustitución con antagonistas-GnRh surgió como una alternativa mediante la cual se reduce el consumo de gonadotropinas y la duración del tratamiento. ${ }^{18}$

\footnotetext{
${ }^{16}$ Véase sobre ello: CRAVIOTTO VALLE, P., "Embriones en reproducción humana asistida: controversias sobre la congelación y el estudio genético pre-implantatorio", Revista electrónica IUS ET SCIENTIA, vol. 5, $\mathrm{n}^{\circ}$. 1, 2019, p. 78. Disponible en: https://institucional.us.es/iusetscientia/index.php/ies/article/view/165/118 (Consultado el 27 de julio de 2019).

${ }^{17}$ RODRÍGUEZ ZURRO, L. (2016). Donación de ovocitos en reproducción humana asistida. Cuidados de Enfermería, Trabajo de fin de grado, VELÁZQUEZ BARBADO, M. R. y DEL PINO ORTEGA, M. C. (dir.), Universidad de Valladolid, Valladolid, 2016. Disponible en: http://uvadoc.uva.es/bitstream/handle/10324/18044/TFG-H510.pdf?sequence=1\&isAllowed=y (Consultado el 27 de julio de 2019).

${ }^{18}$ LA MARCA, A. y SUNKARA, S.K., "Individualization of controlled ovarian stimulation in IVF using ovarian reserve markers: from theory to practice", Human Reproduction Update, 20(1), 2014, pp. 124-140. Disponible en: https://www.researchgate.net/publication/257206176_Individualization_of_controlled_ovarian_sti
} 
IUS ET SCIENTIA (ISSN 244-8478) 2019, Vol. 5, nº 2, pp. 11-54 LA DONACIÓN DE ÓVULOS EN LA REPRODUCCIÓN ASISTIDA: RIESGOS Y RESPONSABILIDAD. Belén Avilés Alepuz y Francisca Ramón Fernández, Universidad Politécnica de Valencia, beaval@etsiamn.upv.es, frarafer@urb.upv.es Recibido: 17/09/2019. Aceptado: 10/10/2019 DOI: http://doi.org/10.12795/IESTSCIENTIA.2019.i02.03

Aunque ambos protocolos han demostrado tener una eficacia comparable, el uso de antagonistas-GnRh implica que el reclutamiento folicular inicial tiene lugar por estimulación de los factores endocrinos endógenos, anteriormente a la administración externa de gonadotropinas. Es por ello que el número de folículos en crecimiento es menor comparado con el protocolo de agonistas- GnRh, ${ }^{19}$ lo que es una ventaja en mujeres con elevada reserva ovárica, como es el caso de las donantes, para evitar complicaciones como el síndrome de hiperestimulación ovárica $(\mathrm{SHO}){ }^{20}$

La posterior estimulación ovárica se favorece mediante la administración de hormonas folículo estimulantes (FSH) y hormonas luteinizantes (LH). La FSH es secretada en condiciones fisiológicas normales por las células gonadotróficas de la hipófisis bajo estímulo de las GnRh, regulando el crecimiento folicular. Un aumento prolongado de la FSH permite el reclutamiento y posterior maduración de un mayor número de folículos en un mismo ciclo, permitiendo la superovulación. $^{21}$

La LH es otra hormona gonadotrópica producida por la hipófisis, en condiciones fisiológicas un pico en la concentración de LH induce la ovulación y entrada en la fase folicular lútea. La administración de LH en los tratamientos de reproducción asistida permite la maduración final del folículo, pero dada la concentración regulada que se administra, no llega a producirse la ovulación. ${ }^{22}$

Por último, una vez determinado mediante ecografía que se ha producido la maduración exitosa de dos o más folículos con un diámetro entre 18-20 mm se administra la hormona gonadotropina coriónica humana (hCG) ${ }^{23}$ para

mulation_in_IVF_using_ovarian_reserve_markers_From_theory_to_practice (Consultado el $25 \mathrm{de}$ julio de 2019).

${ }^{19}$ LA MARCA, A. y SUNKARA, S.K., "Individualization of controlled ovarian stimulation in IVF using ovarian reserve markers: from theory to practice", cit., p. 130 y ss.

${ }^{20}$ NELSON, S.M., YATES, R.W., LYALL, H., JAMIESON, M., TRAYNOR, I., GAUDOIN, M., MITCHELL, P., AMBROSE, P., y FLEMING, R., "Anti-Müllerian hormone-based approach to controlled ovarian stimulation for assisted conception", Human Reproduction, 24(4), 2009, pp. 867-875.

${ }^{21}$ FRÍAS INIESTA, J., “¿Hay diferencias entre las gonadotropinas disponibles para la estimulación ovárica en técnicas de reproducción asistida?", Progresos de obstetricia y ginecología. Revista oficial de la Sociedad Española de Ginecología y Obstetricia, 51(5), 2008, pp. 281-300.

${ }^{22}$ FRÍAS INIESTA, J., “¿Hay diferencias entre las gonadotropinas disponibles para la estimulación ovárica en técnicas de reproducción asistida?", cit., p. 290 y ss.

${ }^{23}$ DOLZ, M., DÍAZ-GARCÍA DONATO, J., MARTIN, V., MORENO, X., BENAVENT, M., 
IUS ET SCIENTIA (ISSN 244-8478) 2019, Vol. 5, nº 2, pp. 11-54 LA DONACIÓN DE ÓVULOS EN LA REPRODUCCIÓN ASISTIDA: RIESGOS Y RESPONSABILIDAD. Belén Avilés Alepuz y Francisca Ramón Fernández, Universidad Politécnica de Valencia, beaval@etsiamn.upv.es, frarafer@urb.upv.es Recibido: 17/09/2019. Aceptado: 10/10/2019 DOI: http://doi.org/10.12795/IESTSCIENTIA.2019.i02.03

desencadenar la ovulación en un momento preciso que servirá para programar la extracción de ovocitos aproximadamente 35 horas después. ${ }^{24}$

Punción ovárica: Consiste en la punción ovárica y aspiración folicular con anestesia general mediante una sonda transvaginal con control ecográfico que dura entre 15 y 30 minutos. $^{25}$

Seguimiento: Tras la punción la paciente debe permanecer en el centro 1-3 horas hasta que terminan los efectos de la sedación. Pasado este tiempo la paciente puede desplazarse a su domicilio bajo la indicación de que permanezca en reposo el resto del día.

Pasadas 4-6 semanas tras la punción se recomienda realizar una revisión para comprobar que la recuperación es correcta.

En cuanto a los riesgos derivados del procedimiento de obtención de óvulos, no existe consenso en la literatura actual en este aspecto y muchos autores defienden que no hay estudios, máxime evaluando los riesgos a largo plazo, que demuestren con certeza y sin lugar a dudas que no existen efectos secundarios y que este procedimiento sea, por tanto, seguro para la salud de las donantes.

Tampoco existe consenso entre los riesgos reconocidos por las clínicas de fertilidad y la Comisión Nacional de Reproducción Humana Asistida. Entre los efectos secundarios reconocidos por algunas de las clínicas que ofrecen la donación de óvulos se encuentran: "molestia y distensión, similar a la de un síndrome premenstrual"26," "cambios de humor y sensibilidad en los senos",27, "pocas molestias", "molestias típicas de la regla". ${ }^{28}$

Sin embargo, los riesgos que la Comisión Nacional de Reproducción Humana

GIJÓN, L. y PONS, J., "Protocolo con antagonistas de la GnRH y maduración final con bolo de agonista en un programa de donación de ovocitos", Revista Iberoamericana de Fertilidad, 24(4), 2006, pp. 245- 250. Disponible en: https://docplayer.es/11501077-Protocolo-con-antagonistas-dela-gnrh-y-maduracion-final-con-bolo-de-agonista-en-un-programa-de-donacion-de-ovocitos.html (Consultado el 25 de julio de 2019).

${ }^{24}$ Rodríguez, 2016) (

${ }^{25}$ DOLZ, M., DÍAZ-GARCÍA DONATO, J., MARTIN, V., MORENO, X., BENAVENT, M., GIJÓN, L. y PONS, J., "Protocolo con antagonistas de la GnRH y maduración final con bolo de agonista en un programa de donación de ovocitos", cit., p. 248.

${ }^{26}$ INSTITUTO VALENCIANO DE INFERTILIDAD, Donación de óvulos: todo lo que necesitas saber. Disponible en: https://ivi.es/blog/donacion-de- ovulos-todo-lo-que-necesitas-saber/ (Consultado el 9 de mayo de 2019).

27 VITA, Medicina reproductiva. Donantes de óvulos. Disponible en: http://www.vitafertilidad.com/donantes/ovulos (Consultado el 9 de mayo de 2019).

28 (FECUNDACIÓN IN VITRO VALENCIA, Donación de óvulos. Disponible en: https://www.fiv-valencia.es/donar-ovulos-valencia/\#gref (Consultado el 9 de mayo de 2019). 
IUS ET SCIENTIA (ISSN 244-8478) 2019, Vol. 5, nº 2, pp. 11-54 LA DONACIÓN DE ÓVULOS EN LA REPRODUCCIÓN ASISTIDA: RIESGOS Y RESPONSABILIDAD. Belén Avilés Alepuz y Francisca Ramón Fernández, Universidad Politécnica de Valencia, beaval@etsiamn.upv.es, frarafer@urb.upv.es Recibido: 17/09/2019. Aceptado: 10/10/2019 DOI: http://doi.org/10.12795/IESTSCIENTIA.2019.i02.03

Asistida atribuyen a la donación de óvulos son más amplios Debido a la disparidad entre los riesgos reconocidos por el Ministerio de Sanidad, Consumo y Bienestar Social y las clínicas que llevan a cabo estas técnicas, muchos autores defienden que el consentimiento informado no es tal, dado que las clínicas de fertilidad tienden a minimizar los riesgos de este procedimiento a la hora de informar a las futuras donantes.

Entre la literatura científica que trata de evaluar la incidencia de dichas complicaciones, los resultados varían de forma significativa en función de los criterios seguidos en cuanto a la planificación del estudio, entre otros: los requisitos para formar la cohorte de donantes, el protocolo seguido para la hiperestimulación o los criterios para la evaluación de las complicaciones. A continuación, se expondrán los resultados de algunos de los estudios consultados.

En un estudio retrospectivo llevado a cabo entre 1987 y 2001 por Sauer, cuyo resultado fue publicado en 2001, se estudiaron 1000 casos de extracción de ovocitos. Entre los casos estudiados, solamente tuvieron lugar 7 eventos de relevancia médica significativa $(0.7 \%$ de incidencia). Se dieron 3 casos de síndrome de ovario poliquístico severo que requirió hospitalización y soporte intravenoso, 2 casos de reacción severa a la anestesia intravenosa que provocó que las donantes se mostrasen hipotensas y sin respuesta, requiriendo ventilación asistida durante varios minutos hasta que los fármacos de la anestesia fueron revertidos y 2 casos de hemorragia tras la aspiración folicular, uno de ellos por sangrado intra-abdominal y el otro caso por retención urinaria y sangrado en la orina que requirió catéter de irrigación urinario y drenaje durante 24 horas. $^{29}$

Este estudio ha sido ampliamente citado en la literatura que trata de abarcar los riesgos asociados a la donación de ovocitos ${ }^{30}$ por ser su autor uno de los primeros

\footnotetext{
${ }^{29}$ SAUER, M. V., "Defining the incidence of serious complications experienced by oocyte donors: a review of 1000 cases", American journal of obstetrics and gynecology, 184(3), 2001, pp. 277278.

${ }^{30}$ Entre otros, BODRI, D., GUILLÉN, J., POLO, A., TRULLENQUE, M., ESTEVE, C. y COLL, O., "Complications related to ovarian stimulation and oocyte retrieval in 4052 oocyte donor cycles", Reproductive biomedicine online, 17(2), 2008, pp. 237-243. Disponible en: https://www.rbmojournal.com/article/S1472-6483(10)60200-3/pdf (Consultado el 25 de julio de 2019); JAYAPRAKASAN, K., HERBERT, M., MOODY, E., STEWART, J.A. Y MURDOCH, A.P., "Estimating the risks of ovarian hyperstimulation syndrome (OHSS): implications for egg donation for research", Human Fertility, 10(3), 2007, pp. 183-187. Disponible en: https://www.researchgate.net/profile/Kannamannadiar_Jayaprakasan/publication/6053198_Estimat ing_the_risks_of_ovarian_hyperstimulation_syndrome_OHSS_Implications_for_egg_donation_fo
} 
IUS ET SCIENTIA (ISSN 244-8478) 2019, Vol. 5, nº 2, pp. 11-54 LA DONACIÓN DE ÓVULOS EN LA REPRODUCCIÓN ASISTIDA: RIESGOS Y RESPONSABILIDAD. Belén Avilés Alepuz y Francisca Ramón Fernández, Universidad Politécnica de Valencia, beaval@etsiamn.upv.es, frarafer@urb.upv.es Recibido: 17/09/2019. Aceptado: 10/10/2019 DOI: http://doi.org/10.12795/IESTSCIENTIA.2019.i02.03

en emprender esta tarea y por la implicación de su autor en este menester.

Más recientemente, Bodri et al. en un ensayo realizado entre 2001 y 2007 y publicado en $2008^{31}$, llevaron a cabo un estudio similar analizando un total de 4052 ciclos cuyo objetivo no era únicamente recopilar los riesgos asociados a la extracción de ovocitos sino que también trataron de observar diferencias significativas en cuanto a las dificultadas asociadas a los dos tipos de tratamientos mencionados; aquellos en los que para la estimulación se emplean agonistasGnRH y en los que se emplean antagonistas- GnRH.

Entre las pacientes observadas por Bodri et $a l^{32}$, un total de 14 fueron diagnosticadas por sangrado intra-abdominal $(0.35 \%)$ de las cuales 11 tuvieron que ser hospitalizadas: cinco requirieron cirugía $(0.12 \%)$, cuatro pacientes por laparoscopia -una de las cuales requirió además transfusión- y una por laparotomía.

Hubo un único caso de torsión ovárica unilateral $(0.024 \%)$ en una paciente que tuvo que ser operada por laparoscopia, afortunadamente la operación fue un éxito y el ovario resultó intacto.

No se observaron casos de infecciones pélvicas ni daño de las estructuras anatómicas tras la aspiración folicular.

Se diagnosticó SHO de grado moderado o severo en 22 pacientes $(0.54 \%)$ durante las primeras semanas después de la aspiración, todos los casos se dieron en pacientes que habían sido tratadas con rHCG para la estimulación. De los 22 casos de SHO, 11 de ellos requirieron hospitalización durante un periodo de 1 a 9 días. En todos los casos hubo una recuperación completa de las pacientes pasadas las dos semanas tras la aspiración.

Otro estudio de actualidad relativa es el llevado a cabo por Kramer et al. realizado y publicado en $2009^{33}$ en Estados Unidos en el que se recopiló información vía

r_research/links/02e7e528e5d41acee2000000/Estimating-the-risks-of-ovarian-hyperstimulationsyndrome-OHSS-Implications-for-egg-donation-for-research.pdf (Consultado el 26 de julio de 2019).

31 BODRI, D., GUILlÉN, J., POlO, A., TRULlenQue, M., ESTEVE, C. y COLL, O., "Complications related to ovarian stimulation and oocyte retrieval in 4052 oocyte donor cycles", cit., p. 240 y sigs.

32 BODRI, D., GUILlÉN, J., POLO, A., TRULlENQUe, M., ESTEVE, C. y COLL, O., "Complications related to ovarian stimulation and oocyte retrieval in 4052 oocyte donor cycles", cit., p. 240 y sigs.

${ }^{33}$ KRAMER, W., SCHNEIDER, J. y SCHULTZ, N., "US oocyte donors: a retrospective study of 
IUS ET SCIENTIA (ISSN 244-8478) 2019, Vol. 5, nº 2, pp. 11-54 LA DONACIÓN DE ÓVULOS EN LA REPRODUCCIÓN ASISTIDA: RIESGOS Y RESPONSABILIDAD. Belén Avilés Alepuz y Francisca Ramón Fernández, Universidad Politécnica de Valencia, beaval@etsiamn.upv.es, frarafer@urb.upv.es Recibido: 17/09/2019. Aceptado: 10/10/2019 DOI: http://doi.org/10.12795/IESTSCIENTIA.2019.i02.03

telemática relativa a las complicaciones médicas físicas y psíquicas sufridas por las pacientes durante la donación de óvulos y la relación de las donantes con las clínicas y familias que lograron concebir a partir de sus óvulos (posibilidad que la legislación estadounidense ofrece a diferencia de la española, en la que la identidad de donantes y usuarios de las técnicas que reciben los óvulos es estrictamente confidencial). Aunque la información recopilada puede ser cuestionada dado que se basa en el testimonio dado por las donantes, resulta de interés por su carácter retrospectivo al evaluar los resultados de la extracción de ovocitos de 1 a 22 años después.

Un total de 155 mujeres seleccionadas del "Donor Sibling Registry" accedieron a participar en el estudio respondiendo a un formulario formado por un total de 25 cuestiones.

De las 155 pacientes encuestadas, 47 participantes (30.3\%) reportaron haber sufrido SHO en alguno de sus grados de gravedad. A consecuencia del SHO 18 de las pacientes (11.6\%) tuvieron que ser hospitalizadas y/o sometidas a paracentesis. Subsecuentes a la donación, 41 mujeres (26.4\%) declararon haber sufrido problemas de infertilidad y/o haber sufrido cambios en el ciclo menstrual. De las 15 donantes $(9.6 \%)$ que reportaron problemas infertilidad solamente 4 lograron finalmente quedar embarazadas.

Una mujer con antecedentes familiares de cáncer de mamas desarrolló ese mismo tipo de cáncer a la edad de 41, 12 años después de la donación, y una única mujer más fue diagnosticada de melanoma a la edad de 35 años

Otro de los efectos de la extracción de ovocitos reportados son los embarazos no deseados. Las píldoras anticonceptivas, de uso muy extendido entre las mujeres con edad de donar óvulos, están contraindicadas durante el protocolo de obtención de óvulos por lo que las pacientes han de emplear métodos barrera para prevenir el embarazo, los cuales fallaron en su aplicación o uso en un $7 \%$ de las mujeres. ${ }^{34}$ Como se ha comentado anteriormente, el riesgo más frecuente derivado del

medical and psychosocial issues", Human reproduction, 24(12), 2009, pp. 3144-3149. Disponible en:

https://www.researchgate.net/publication/26788590_US_oocyte_donors_A_retrospective_study_o f_medical_and_psychosocial_issues (Consultado el 25 de julio de 2019).

${ }^{34}$ SAUER, M. V. y PAULSON, R. J., "Mishaps and misfortunes: complications that occur in oocyte donation", Fertility and sterility, 61(5), 1994, pp. 963-965. Disponible en: https://www.fertstert.org/article/S0015-0282(16)56713-2/pdf (Consultado el 27 de julio de 2019). 
IUS ET SCIENTIA (ISSN 244-8478) 2019, Vol. 5, nº 2, pp. 11-54 LA DONACIÓN DE ÓVULOS EN LA REPRODUCCIÓN ASISTIDA: RIESGOS Y RESPONSABILIDAD. Belén Avilés Alepuz y Francisca Ramón Fernández, Universidad Politécnica de Valencia, beaval@etsiamn.upv.es, frarafer@urb.upv.es Recibido: 17/09/2019. Aceptado: 10/10/2019 DOI: http://doi.org/10.12795/IESTSCIENTIA.2019.i02.03

procedimiento de extracción de ovocitos es el de sufrir SHO. La frecuencia de sufrir dicho síndrome oscila según los estudios comentados entre el $0.3 \%{ }^{35}$ y el $0.54 \%{ }^{36}$ por ciclo. Los datos del estudio retrospectivo realizado por Kramer et al. publicado en 2009 no son comparables dado que los porcentajes ofrecidos indican la frecuencia con la que se dio cierta dificultad relativa al total de mujeres que donaron y no al número de ciclos de donación que se estudiaron, el número de ciclos por mujer oscila entre los 1 y 12 por mujer.

La probabilidad de sufrir un ingreso hospitalario a raíz de un problema derivado de la extracción de ovocitos es de $0.35 \%$ por ciclo. ${ }^{37} \mathrm{El}$ estudio retrospectivo determinó que 18 de las 155 mujeres encuestadas (11.6\%) hubieron de ser hospitalizadas, ${ }^{38}$ datos similares a los obtenidos en el estudio dirigido por Jayaprakasan et al en el cual se dieron 49 hospitalizaciones de un total 339 donantes. $^{39}$

Entre los riesgos más sensacionalistas asociados a la obtención de óvulos destacan la infertilidad y el cáncer.

En un estudio en el que se evaluó la cantidad y calidad de los óvulos de mujeres que se habían sometido a cinco o menos ciclos de estimulación folicular se determinó que no existía riesgo alguno en cuanto a la respuesta ovárica asociado a dichos tratamientos. ${ }^{40}$ Sin embargo, el tratamiento hormonal con el que se trata a las pacientes previo a la extracción de ovocitos sí que se ha visto asociado a un rápido avance de la endometriosis en mujeres no diagnosticadas que, en casos graves, puede desencadenar en problemas de infertilidad. ${ }^{41}$ El estudio de Kramer

\footnotetext{
${ }^{35}$ SAUER, M. V., "Defining the incidence of serious complications experienced by oocyte donors: a review of 1000 cases", cit., p. 271 y s.

${ }^{36}$ BODRI, D., GUILlÉN, J., POlO, A., TRUllenQue, M., ESTEVe, C. y COLl, O., "Complications related to ovarian stimulation and oocyte retrieval in 4052 oocyte donor cycles", cit., p. 240 y ss.

37 BODRI, D., GUILlÉN, J., POLO, A., TRULlenQue, M., ESTEVE, C. y COLL, O., "Complications related to ovarian stimulation and oocyte retrieval in 4052 oocyte donor cycles", cit., p. 240 y sigs.

${ }^{38}$ KRAMER, W., SCHNEIDER, J. y SCHULTZ, N., "US oocyte donors: a retrospective study of medical and psychosocial issues", cit., p. 3145 y ss.

${ }^{39}$ JAYAPRAKASAN, K., HERBERT, M., MOODY, E., STEWART, J.A. Y MURDOCH, A.P., "Estimating the risks of ovarian hyperstimulation syndrome (OHSS): implications for egg donation for research", cit., p. 185.

${ }^{40}$ CALIGARA, C., NAVARRO, J., VARGAS, G., SIMÓN, C., PELLICER, A., REMOHÍ, J., 'The effect of repeated controlled ovarian stimulation in donors", Human Reproduction, 16(11), 2001, pp. $2320-2323$.

${ }^{41}$ AL-AZEMI, M., LÓPEZ BERNAL, A., STEELE, J., GRAMSBERGEN, I., BARLOW, D. Y
} 
IUS ET SCIENTIA (ISSN 244-8478) 2019, Vol. 5, nº 2, pp. 11-54 LA DONACIÓN DE ÓVULOS EN LA REPRODUCCIÓN ASISTIDA: RIESGOS Y RESPONSABILIDAD. Belén Avilés Alepuz y Francisca Ramón Fernández, Universidad Politécnica de Valencia, beaval@etsiamn.upv.es, frarafer@urb.upv.es Recibido: 17/09/2019. Aceptado: 10/10/2019 DOI: http://doi.org/10.12795/IESTSCIENTIA.2019.i02.03

et al., ${ }^{42}$ concluye que un $9.6 \%$ de las donantes entrevistadas refirió problemas de infertilidad, no obstante, dado que la media edad de estas mujeres en el momento es de 26.4 años de edad, la mayoría no había hecho ningún intento de quedarse embarazada antes de someterse al procedimiento de extracción. ${ }^{43}$

El cáncer también se ha considerado otro posible riesgo de realizar donaciones de óvulos de manera repetida, cinco fueron los casos de mujeres que reportaron haber sufrido de algún tipo de cáncer en el artículo de Schneider et al. ${ }^{44}$ Sin embargo, nunca se observó una relación causal entre el consumo de hormonas inductoras de la ovulación del tratamiento de extracción de ovocitos y cáncer de ovario en el estudio danés realizado con una cohorte de 54.362 mujeres diagnosticadas de infertilidad. $^{45}$

Los riesgos a corto plazo asociados al tratamiento de estimulación ovárica y la posterior cirugía son ampliamente conocidos por los profesionales del sector y estos son, en su mayoría, de baja incidencia y recuperación completa si las pacientes siguen las indicaciones proporcionadas por los profesionales. Tanto la frecuencia como gravedad de los efectos adversos han decrecido en las últimas décadas desde que surgieron los primeros protocolos debido a la mejora de estos y, dada la demanda y eficacia de los TRHA, cabe esperar que futuras investigaciones permitan minimizar estos riesgos aún más. Sin embargo, datándose las primeras donaciones de óvulos hace tan solo unos 30 años y sin un registro de donantes que permita un correcto seguimiento médico de estas pacientes, no es posible determinar los riesgos a largo plazo asociados a los procedimientos de extracción de ovocitos. La falta de estudios que demuestren la relación causal entre el procedimiento y los riesgos no determina la falta de

KENNEDY S., "Ovarian response to repeated controlled stimulation in in-vitro fertilization cycles in patients with ovarian endometriosis", Human Reproduction, 15(1), 2000, pp. 72-75. Disponible en: https://academic.oup.com/humrep/article/15/1/72/702024 (Consultado el 25de julio de 2019).

${ }^{42}$ KRAMER, W., SCHNEIDER, J. y SCHULTZ, N., "US oocyte donors: a retrospective study of medical and psychosocial issues", cit., p. 3145 y ss.

${ }^{43}$ KRAMER, W., SCHNEIDER, J. y SCHULTZ, N., "US oocyte donors: a retrospective study of medical and psychosocial issues", cit., p. 3146 y ss.

${ }^{44}$ SCHNEIDER, J., LAHL, J. y KRAMER, W., "Long-term breast cancer risk following ovarian stimulation in young egg donors: a call for follow-up, research and informed consent", Reproductive biomedicine online, 34(5), 2017, pp. 480-485.

45 JENSEN, A., SHARIF, H., FREDERIKSEN, K. y KJAER, S.K., "Use of fertility drugs and risk of ovarian cancer: Danish Population Based Cohort Study", BMJ, 2009;338:b249. Disponible en: https://www.bmj.com/content/338/bmj.b249 (Consultado el 24 de julio de 2019). 
IUS ET SCIENTIA (ISSN 244-8478) 2019, Vol. 5, nº 2, pp. 11-54 LA DONACIÓN DE ÓVULOS EN LA REPRODUCCIÓN ASISTIDA: RIESGOS Y RESPONSABILIDAD. Belén Avilés Alepuz y Francisca Ramón Fernández, Universidad Politécnica de Valencia, beaval@etsiamn.upv.es, frarafer@urb.upv.es Recibido: 17/09/2019. Aceptado: 10/10/2019 DOI: http://doi.org/10.12795/IESTSCIENTIA.2019.i02.03

estos. $^{46}$

\section{PRestación deL CONSENTIMIENTO INFORMAdo}

Anteriormente se indicó que uno de los requisitos para que se pueda llevar a cabo la intervención de donación de óvulos (al igual que toda actuación en el ámbito de la sanidad) es obtener el consentimiento informado del paciente en virtud del Artículo 5.4 de la Ley 14/2006. El consentimiento informado constituye una figura ética y legal exigible al profesional de la medicina que se disponga a llevar acabo cualquier intervención médica en virtud de la Ley 41/2002, de 14 de noviembre, básica reguladora de la autonomía del paciente y de derechos y obligaciones en materia de información y documentación clínica ${ }^{47}$ (en adelante Ley 41/2002) constituyendo, por tanto, un elemento esencial de la lex artis.

La Ley 41/2002 Artículo 2.1 orienta la obligación de informar al paciente en virtud de proteger su dignidad y el respeto a la autonomía de su voluntad. El paciente tiene derecho, tal como estipula el Artículo 2.2 de la Ley 41/2002, a recibir la información por parte de cualquier profesional que intervenga en la actividad asistencial, de forma objetiva y comprensible a sus capacidades, de forma tal que pueda decidir libremente, después de haber recibido la información adecuada, entre las opciones clínicas disponibles (Artículo 2.3). Del mismo modo, el paciente tiene derecho a la no información. (Artículo 4.1)

El derecho a la información cobra fuerza pues en los supuestos de "medicina voluntaria” en los que la obligación de informar se acentúa con el fin de que el paciente o cliente conozca los riesgos o pormenores de la intervención para poderlos evaluar y en base a ello, consentirla o desistir de ella, tratándose de una intervención innecesaria o de necesidad relativa, como indicó la STS de 21 de octubre de $2005 .^{48}$

Es por ello que el TS ha subrayado la especial relevancia de la información en estos

\footnotetext{
${ }^{46}$ SCHNEIDER, J., LAHL, J. y KRAMER, W., "Long-term breast cancer risk following ovarian stimulation in young egg donors: a call for follow-up, research and informed consent”, cit., p. 482.

${ }^{47}$ BOE número 41, de 14 de noviembre de 2002.

${ }^{48}$ ROJ: STS 6400/2005, ECLI: ES:TS:2005:6400. Ponente: Jesús Eugenio Corbal Fernández.
} 
IUS ET SCIENTIA (ISSN 244-8478) 2019, Vol. 5, nº 2, pp. 11-54 LA DONACIÓN DE ÓVULOS EN LA REPRODUCCIÓN ASISTIDA: RIESGOS Y RESPONSABILIDAD. Belén Avilés Alepuz y Francisca Ramón Fernández, Universidad Politécnica de Valencia, beaval@etsiamn.upv.es, frarafer@urb.upv.es Recibido: 17/09/2019. Aceptado: 10/10/2019 DOI: http://doi.org/10.12795/IESTSCIENTIA.2019.i02.03

casos como en la STS de 25 de abril de $1994^{49}$, para evitar que se dé el silenciamiento de los riesgos potenciales de la intervención por parte de las clínicas que lo llevasen a cabo, y evitar así que los usuarios rehúsen someterse a estas. $^{50}$

A raíz de esta información se puede determinar sin lugar a duda que el procedimiento al que se someten las donantes de óvulos entra dentro de la definición de medicina voluntaria. Por ello, cabe esperar que la información ofrecida por los médicos y profesionales sanitarios de las clínicas en las cuales se lleva a cabo esta intervención, cumpla con las rigurosas exigencias del TS para estos casos a la hora de informar a sus clientas. Máxime cuando determina el TS que "como información objetiva, veraz, completa y asequible, no solo comprende las posibilidades de fracaso de la intervención, es decir, el pronóstico sobre las probabilidades del resultado, sino que también se debe advertir de cualesquiera secuelas, riesgos, complicaciones o resultados adversos se puedan producir, sean de carácter permanente o temporal, y con independencia de su frecuencia y de que la intervención se desarrolle con plena corrección técnica". 51

Se espera por ello de las clínicas que ofrecen la posibilidad de donar óvulos informen de todos los riesgos asociados a dicha intervención, pese a la baja probabilidad y durabilidad de estos, siendo además infrecuente la existencia de efectos secundarios a largo plazo. Sin embargo, citados anteriormente los riesgos que las clínicas asocian a esta intervención (en su mayoría dolores similares al síndrome premenstrual) se incumple, en mi opinión, el deber de informar debidamente a estas usuarias. La minusvaloración de los riesgos asociados puede seguir el objetivo de que las mujeres sanas no rehúsen someterse a esta intervención necesaria para llevar a cabo las técnicas de reproducción humana asistida con óvulos de donantes, que ofrece la mayor tasa de éxito entre las diferentes técnicas de reproducción asistida, generando importantes beneficios económicos para las clínicas que las llevan a cabo, existiendo un acusante conflicto de intereses.

\footnotetext{
${ }^{49}$ ROJ: STS 2851/1994 - ECLI:ES:TS:1994:2851. Ponente: José Luis Albácar López.

${ }^{50}$ LÓPEZ y LÓPEZ, A., VALPUESTA FERNÁNDEZ, M. R. y SERRANO FERNÁNDEZ, M., Tratado jurisprudencial de responsabilidad por daños, Tirant lo Blanch, Valencia, 2013.

${ }^{51}$ STS de 21 de octubre de 2005, ROJ: STS 6400/2005, ECLI: ES:TS:2005:6400. Ponente: Jesús Eugenio Corbal Fernández.
} 


\section{RESPONSABILIDAD EN EL ÁMBITO JURÍDICO Y EN RELACIÓN CON LA DONACIÓN DE Óvulos EN EL ÁMBITO DE LAS TÉCNICAS DE REPRODUCCIÓN ASISTIDA}

A continuación, serán brevemente descritos los tres ámbitos de responsabilidad jurídica en los que se puede incurrir al producirse un daño ocasionado por un acto médico:

a) Responsabilidad civil, distinguiendo la contractual y extracontractual. La responsabilidad contractual (Artículo $1091 \mathrm{CC}$ ) proviene en el caso de las TRHA, del incumplimiento de alguna de las obligaciones contraídas con los usuarios de dichas técnicas. ${ }^{52}$

La responsabilidad extracontractual (Artículo 1902 CC) surge por el principio general de comportamiento neminem laedere, por el incumplimiento del deber de no causar daño a nadie ${ }^{53}$ independientemente de la existencia o no de cualquier relación jurídica preexistente entre las distintas partes.

b) Responsabilidad administrativa que tiene como objeto reprimir lo que se considera una ofensa al conjunto de la sociedad tal que el atentado contra la pacífica convivencia no tenga entidad suficiente como para justificar una condena penal. Ante un hecho punible la sanción será penal o administrativa, pero nunca se sancionará a un sujeto infractor por el mismo hecho punible con una sanción penal y administrativa.

c) Responsabilidad penal, que se origina por un acto antijurídico contemplado en

el Código Penal de $1995^{54}$ como delito, sufriendo una sanción penal en las condiciones y formas descritas por la ley.

52 DÍAZ MARTÍNEZ, A., "Responsabilidad por daños en la aplicación de técnicas de reproducción asistida: diferencias con la investigación biomédica (a propósito de las SSTS de 23 de octubre de 2008 y 20 de noviembre de 2009)", Revista de derecho y genoma humano: genética, biotecnología y medicina avanzada. (32), 2010, pp. 193-218. Disponible en: https://mega.nz/\#!SdklEBLR!c0NSYS4e611GFkqxhWGgLGPoZagJkgR_LUk30f5gNlA (Consultado el 27 de julio de 2019).

${ }_{53}$ DÍAZ MARTÍNEZ, A., "Responsabilidad por daños en la aplicación de técnicas de reproducción asistida: diferencias con la investigación biomédica (a propósito de las SSTS de 23 de octubre de 2008 y 20 de noviembre de 2009)", cit., p. 200 y ss.

${ }^{54}$ BOE número 10, de 23 de noviembre de 1995. 
IUS ET SCIENTIA (ISSN 244-8478) 2019, Vol. 5, nº 2, pp. 11-54 LA DONACIÓN DE ÓVULOS EN LA REPRODUCCIÓN ASISTIDA: RIESGOS Y RESPONSABILIDAD. Belén Avilés Alepuz y Francisca Ramón Fernández, Universidad Politécnica de Valencia, beaval@etsiamn.upv.es, frarafer@urb.upv.es Recibido: 17/09/2019. Aceptado: 10/10/2019 DOI: http://doi.org/10.12795/IESTSCIENTIA.2019.i02.03

La responsabilidad penal descansa en la idea de culpabilidad con alcance personal, solo aquel que ha intervenido en el hecho punible puede ser considerado penalmente responsable. La intervención del individuo puede ser como autor, coautor, instigador, partícipe y/o encubridor. ${ }^{55}$

Como se ha comentado, la responsabilidad civil puede originarse a raíz de la existencia de un contrato o en ausencia de este (por la obligación de reparar el daño causado, Artículo 1902 CC), así pues, nos referimos a la responsabilidad contractual y a la extracontractual o aquiliana, respectivamente. En el ámbito de los servicios médicos en general y en el de la donación de óvulos en particular, al producirse un daño derivado de la intervención médica, cabe pensar en la aplicación de la responsabilidad contractual, ya que existe entre médico y paciente un acuerdo entre ambas partes. Sin embargo, en aquellos supuestos en los que se daña la vida, salud o integridad física de las personas, las exigencias de responsabilidad a médicos y personal facultativo puede también basarse en las normas de responsabilidad extracontractual. ${ }^{56}$ Es decir, en el caso de que se produjese un daño al paciente se considera que el médico o profesional facultativo ha incurrido en una vulneración del contrato además de violar el deber general de no dañar a otro, por tanto, existe una yuxtaposición de responsabilidades pudiendo escoger el afectado exigir de ambas responsabilidades para el resarcimiento del daño lo más completo y favorable para la víctima posible.

Por otro lado, cabe comentar la distinción que ha venido haciendo de un tiempo a esta parte el TS en cuanto a la calificación del contrato que liga al paciente con el médico. El TS ha venido diferenciando entre "medicina asistencial" y "medicina satisfactiva". 57

En los supuestos de "medicina asistencial", aquellos en los cuales un paciente se somete a una intervención con el fin de restaurar el bienestar perdido por la presencia de una patología, la obligación sostenida por el médico se considera “obligación de medios". La "obligación de medios" según quedó definido en la

55 RODRÍGUEZ JORDÁN, M., Mala Praxis Médica: Responsabilidad penal, civil y administrativa, Ediciones Ciudad Argentina, Buenos Aires, 1999.

${ }^{56}$ LÓPEZ y LÓPEZ, A., VALPUESTA FERNÁNDEZ, M. R. y SERRANO FERNÁNDEZ, M., Tratado jurisprudencial de responsabilidad por daños, cit., p. 25.

${ }^{57}$ STS, de 3 de febrero de 2015. ROJ: STS 206/2015 - ECLI: ES:TS:2015:206. Ponente: José Antonio Seijas Quintana. 
IUS ET SCIENTIA (ISSN 244-8478) 2019, Vol. 5, nº 2, pp. 11-54 LA DONACIÓN DE ÓVULOS EN LA REPRODUCCIÓN ASISTIDA: RIESGOS Y RESPONSABILIDAD. Belén Avilés Alepuz y Francisca Ramón Fernández, Universidad Politécnica de Valencia, beaval@etsiamn.upv.es, frarafer@urb.upv.es Recibido: 17/09/2019. Aceptado: 10/10/2019 DOI: http://doi.org/10.12795/IESTSCIENTIA.2019.i02.03

STS, de 26 de mayo de $19866^{58}$, obliga al médico o responsable sanitario "no a curar al enfermo, sino a suministrarle los cuidados que requiere según el estado actual de la ciencia médica".

El médico tiene, por tanto, en virtud de las obligaciones contractuales adquiridas con el paciente, la obligación de emplear los medios adecuados a su alcance y actuar con la pericia y diligencia propia de un profesional medio, de manera que su actuación se rija por la denominada lex artis ad hoc o "modulo rector de todo acto médico" como es definido por la STS del 11 de marzo de $1991,{ }^{59}$ entre otras.

La llamada lex artis ad hoc es un término que define la diligencia exigible a todo acto o tratamiento médico, que comporta tanto el cumplimiento formal $\mathrm{y}$ protocolar de las técnicas previstas según el estado de la ciencia como el cuidado y precisión exigibles en la aplicación de tales técnicas, atendiendo a las circunstancias y los riesgos inherentes a cada intervención. ${ }^{60}$

La otra calificación atribuible al contrato entre paciente y médico es la de "obligación de resultados", según la cual siendo todavía de medios "propicia la exigencia de una mayor garantía en la obtención del resultado que se persigue, ya que, si así no sucediera, es obvio que el interesado no acudiría al facultativo para la obtención de la finalidad buscada". 61

Este es el caso de los supuestos de "medicina de carácter voluntario", aquellos en los que el interesado se somete a una intervención no por existir una patología si no en casos como el de mejoramiento de un aspecto físico o estético (medicina estética), transformación de una actividad biológica (vasectomía, ligadura de trompas...) o en el caso que nos ocupa, la cirugía de obtención de óvulos, cuyo resultado esperado es el obtener un número indeterminado de ovocitos (para uso propio o donación) sin efectos secundarios permanentes.

Destaca el TS en la citada sentencia que en estos supuestos de "medicina voluntaria" se intensifica el deber del médico de informar tanto de los posibles riesgos de la intervención como de la posibilidad de que el objetivo buscado por

\footnotetext{
${ }^{58}$ ROJ: STS 2737/1986 - ECLI:ES:TS:1986:2737. Ponente: Jaime Santos Briz.

${ }^{59}$ ROJ: STS 1400/1991 - ECLI:ES:TS:1991:1400. Ponente: Luis Martínez-Calcerrada Gómez.

${ }^{60}$ LÓPEZ y LÓPEZ, A., VALPUESTA FERNÁNDEZ, M. R. y SERRANO FERNÁNDEZ, M., Tratado jurisprudencial de responsabilidad por daños, cit., p. 25.

${ }^{61}$ STS, 25 de abril de 1994, ROJ: STS 2851/1994 - ECLI:ES:TS:1994:2851.Ponente: José Luis Albácar López.
} 
IUS ET SCIENTIA (ISSN 244-8478) 2019, Vol. 5, nº 2, pp. 11-54 LA DONACIÓN DE ÓVULOS EN LA REPRODUCCIÓN ASISTIDA: RIESGOS Y RESPONSABILIDAD. Belén Avilés Alepuz y Francisca Ramón Fernández, Universidad Politécnica de Valencia, beaval@etsiamn.upv.es, frarafer@urb.upv.es Recibido: 17/09/2019. Aceptado: 10/10/2019 DOI: http://doi.org/10.12795/IESTSCIENTIA.2019.i02.03

esta no se cumpla.

Al existir bajo contrato entre médico y paciente, la obligación por parte del médico de alcanzar un resultado, el perjudicado podrá exigir responsabilidad al facultativo no habiendo obtenido dicho resultado, puesto que este habrá incurrido en incumplimiento de contrato. ${ }^{62}$

En cuanto a la responsabilidad administrativa en el ámbito de la donación de óvulos, la Ley 14/2006 contiene numerosas normas de carácter administrativo y sancionador.

El Artículo 26, de Infracciones, de esta misma ley, determina una serie de actuaciones cuya perpetuación incurriría en un incumplimiento de dicha ley y por tanto cabe aplicar sobre los actores responsabilidad administrativa. La Ley 14/2006 clasifica a las mismas como infracciones leves, graves y muy graves. Enumera un total de 10 infracciones muy graves y 12 graves, a la vez que define las leves como aquellas infracciones producidas por el incumplimiento de cualquier obligación o la transgresión de cualquier prohibición establecida por esta Ley, que no están tipificadas como grave o muy grave.

Entre las infracciones enumeradas en la Ley, cabe destacar por el tema que nos ocupa:

- La omisión de la información o los estudios previos necesarios para evitar lesionar los intereses de donantes o usuarios o la transmisión de enfermedades congénitas o hereditarias.

-La ruptura de las condiciones de confidencialidad de los datos de los donantes.

-La retribución económica de la donación de gametos y preembriones o su compensación económica en contra de lo previsto en los artículos 5.3 y 11.6. establecidas en esta Ley.

-La generación de un número de hijos por donante superior al legalmente establecido que resulte de la falta de diligencia del centro o servicio correspondiente en la comprobación de los datos facilitados por los donantes y, en el caso de éstos, el suministro de datos falsos en la identidad o la referencia a otras donaciones previas, como infracciones graves.

\footnotetext{
${ }^{62}$ SERRA RODRÍGUEZ, A., "El contrato de servicios médicos y la lex artis: Comentario a la STS 2 octubre 1997 (RJ 1997, 7405)", Revista Aranzadi de derecho patrimonial, (1), 1998, pp. 167174.
} 
IUS ET SCIENTIA (ISSN 244-8478) 2019, Vol. 5, nº 2, pp. 11-54 LA DONACIÓN DE ÓVULOS EN LA REPRODUCCIÓN ASISTIDA: RIESGOS Y RESPONSABILIDAD. Belén Avilés Alepuz y Francisca Ramón Fernández, Universidad Politécnica de Valencia, beaval@etsiamn.upv.es, frarafer@urb.upv.es Recibido: 17/09/2019. Aceptado: 10/10/2019 DOI: http://doi.org/10.12795/IESTSCIENTIA.2019.i02.03

Tanto las sanciones a imponer como la competencia sancionadora quedan definidas por los Artículos 27 y 28 de esta misma Ley, respectivamente.

Cabe comentar en este contexto la STS, de 23 de mayo de $2011,{ }^{63}$ en la que se confirma la sanción impuesta por la realización por parte de la recurrente de labor médica y analítica en relación al proceso de reproducción asistida humana que está sometida a autorización administrativa de la que carecía la parte sancionada. La sancionada ofrecía la realización de pruebas y análisis andrológicos avanzados, espermiograma y espermocitograma, para las cuales carecía de autrización adminsitrativa. La sentencia consideró que esa actividad está sujeta a autorización en virtud del Artículo 14 de la Ley 35/1988, por lo que se confirmó la sanción impuesta por la Consejería de Salud de la Junta de Andalucía al pago de una multa de 15.025,31 euros, demostrando que la responsabilidad administrativa puede darse en el ámbito médico.

Por último, cabría reclamar responsabilidad penal en un supuesto de negligencia médica dado que el Código Penal (CP) recoge una serie de figuras que afectan o abarcan la actividad de los profesionales, aunque sin existir mención específica a la actividad de los profesionales de la sanidad, como es el caso por ejemplo del CP portugués, si no que ha de hacerse una interpretación extensiva de los diferentes Artículos del CP que puedan aplicarse a este caso, que serán posteriormente citados y analizados individualmente. ${ }^{64}$

La responsabilidad penal puede ser dolosa o culposa. La responsabilidad dolosa implica intencionalidad del autor de conseguir un determinado fin, exige por tanto conciencia, conocimiento y voluntad de obtener dicho resultado. La culpa, por definición, excluye la intencionalidad, abarcando con ello los supuestos de negligencia médica. ${ }^{65}$

Suponiendo como único fin de la actividad médica la búsqueda del beneficio del

${ }^{63}$ ROJ: STS 3912/2011. ECLI:ES:TSJAND:2011:3912. Ponente: Jorge Rafael Muñoz Cortés.

${ }^{64}$ FERNÁNDEZ-SAMBRUNO CLAVER, G. J. (2018). La responsabilidad penal por mala praxis Médica. Tesis de máster, BALBUENA PÉREZ, D. E. (dir.), https://reunir.unir.net/bitstream/handle/123456789/6389/FERNANDEZ-

SAMBRUNO\%20CLAVER\%20GONZALO\%20JUAN.pdf?sequence=1\&isAllowed=y

(Consultado el 27 de julio de 20019).

65 PORTERO LAZCANO, P., "Responsabilidad penal culposa del médico: fundamentos para el establecimiento de la negligencia o impericia", Revista Latinoamericana de Derecho Médico y Medicina Legal, 6(2), 2001, pp. 89-96. Disponible en: https://docplayer.es/4689531Responsabilidad-penal-culposa-del-medico-fundamentos-para-el-establecimiento-de-lanegligencia-o-impericia.html (Consultado el 27 de julio de 2019). 
IUS ET SCIENTIA (ISSN 244-8478) 2019, Vol. 5, nº 2, pp. 11-54 LA DONACIÓN DE ÓVULOS EN LA REPRODUCCIÓN ASISTIDA: RIESGOS Y RESPONSABILIDAD. Belén Avilés Alepuz y Francisca Ramón Fernández, Universidad Politécnica de Valencia, beaval@etsiamn.upv.es, frarafer@urb.upv.es Recibido: 17/09/2019. Aceptado: 10/10/2019 DOI: http://doi.org/10.12795/IESTSCIENTIA.2019.i02.03

paciente, cabría excluir en los profesionales de la medicina los delitos dolosos. No obstante, el CP recoge delitos dolosos cometidos por profesionales (en este caso de la medicina) entre los cuales se encuentran los siguientes;

En primer lugar, el CP en el Capítulo V (Artículos 159 a 162) contempla los delitos relativos a la manipulación genética, prohibiendo la misma con un fin distinto al de la eliminación o disminución de taras o enfermedades graves. La ley 14/2006, sobre TRHA, la Ley 14/2007, de 3 de julio, de Investigación Biomédica $^{66}$ y el Real Decreto 413/1996, de 1 de marzo, por el que se establecen los requisitos técnicos y funcionales precisos para la autorización y homologación de los centros y servicios sanitarios relacionados con las técnicas de reproducción humana asistida ${ }^{67}$ regulan los centros autorizables para llevar a cabo este tipo de técnicas. El CP prevé multa de dos a seis años e inhabilitación profesional de siete a diez a quien manipulase los genes humanos alterando el genotipo. La manipulación genética con fines no terapéuticos o terapéuticos no autorizados también se contempla en la Ley 14/2206 Artículo 26 de Infracciones.

El mismo capítulo V del CP, el Artículo 161 contempla pena de prisión de dos a seis años e inhabilitación profesional a quien aplicare técnicas de reproducción asistida en una mujer sin su consentimiento.

Dada la definición de la donación de gametos aportada por la Ley 14/2006 como un contrato gratuito, formal y confidencial entre la donante y el centro autorizado, el profesional que divulgase secretos sobre los donantes o el acto de donación, incurriría en delito de descubrimiento y revelación de secretos castigado con pena de prisión de uno a cuatro años, multa de doce a veinticuatro meses e inhabilitación de la profesión médica en virtud del Artículos 199 del CP. De nuevo, la ruptura de las condiciones de confidencialidad de las donantes queda recogida por la Ley 14/2006 Artículo 26.4 de Infracciones.

Por otro lado, mencionadas las causas de responsabilidad penal dolosa en la que podrían incurrir los profesionales médicos en al ámbito de la donación de óvulos, cabe determinar la responsabilidad profesional penal por culpa contemplada por el

\footnotetext{
${ }^{66}$ BOE número 14, de 3 de julio de 2007.

${ }^{67}$ BOE número 412, de 1 de marzo de 1996.
} 
IUS ET SCIENTIA (ISSN 244-8478) 2019, Vol. 5, nº 2, pp. 11-54 LA DONACIÓN DE ÓVULOS EN LA REPRODUCCIÓN ASISTIDA: RIESGOS Y RESPONSABILIDAD. Belén Avilés Alepuz y Francisca Ramón Fernández, Universidad Politécnica de Valencia, beaval@etsiamn.upv.es, frarafer@urb.upv.es Recibido: 17/09/2019. Aceptado: 10/10/2019 DOI: http://doi.org/10.12795/IESTSCIENTIA.2019.i02.03

CP a través de la imprudencia. ${ }^{68}$

En este contexto el Artículo 146 del CP relativo al aborto, el cual prevé inhabilitación de uno a tres años del profesional (médico) que por imprudencia cometiere aborto.

Tratándose el tema de negligencia médica no puede quedar sin mención el homicidio por imprudencia profesional (médica), contemplado por el Artículo 142 del CP el cual prevé prisión de uno a cuatro años e inhabilitación para el ejercicio de la profesión de tres a seis años.

Siendo el homicidio por imprudencia profesional médica poco común en el ámbito de la donación de óvulos, sí son frecuentes por el contrario los delitos de lesiones por imprudencia grave contemplados por el Artículo 152 del CP. El CP distingue para el castigo de los delitos de lesiones entre: la imprudencia grave que cause lesiones que menoscaben la integridad corporal o la salud física o mental de la víctima (Artículo 152.1 primero en relación con el Artículo 147.1), penado con prisión de tres a seis meses o multa de seis a dieciocho meses; la imprudencia grave que cause lesiones que suponen la pérdida o inutilidad de un órgano o miembro principal -contemplándose la impotencia o esterilidad - (Artículo 152.1 segundo en relación con el Artículo 149), penado con presión de uno a tres años; imprudencia grave que cause lesiones que provoquen la pérdida o inutilidad de un órgano o miembro no principal o la deformidad (Artículo 152.1 tercero en relación con el Artículo 150), penado de seis meses a dos años. En todos los supuestos se contempla la inhabilitación especial para el ejercicio de la profesión por un periodo de seis meses a cuatro años.

También contempla el CP en Artículo 152.2 los supuestos de causación de lesiones de los Artículos 149 y 150 por imprudencia menos grave, con pena de multa de tres a doce meses.

\section{Análisis de casos}

A) Donación de óvulos en que se produce complicaciones al desoír la paciente las recomendaciones médicas con resultado de extirpación parcial de un ovario A continuación, se procederá a comentar el auto resuelto por SAP Audiencia

${ }^{68}$ PORTERO LAZCANO, P., "Responsabilidad penal culposa del médico: fundamentos para el establecimiento de la negligencia o impericia”, cit., p. 90. 
IUS ET SCIENTIA (ISSN 244-8478) 2019, Vol. 5, nº 2, pp. 11-54 LA DONACIÓN DE ÓVULOS EN LA REPRODUCCIÓN ASISTIDA: RIESGOS Y RESPONSABILIDAD. Belén Avilés Alepuz y Francisca Ramón Fernández, Universidad Politécnica de Valencia, beaval@etsiamn.upv.es, frarafer@urb.upv.es Recibido: 17/09/2019. Aceptado: 10/10/2019 DOI: http://doi.org/10.12795/IESTSCIENTIA.2019.i02.03

Provincial de Madrid (Sección1), de 1 de julio de 2004, ${ }^{69}$ tanto las razones que lo motivaron como las conclusiones aportadas por la Sala, por su relevancia al tratarse de un caso en el que se materializa uno de los riesgos de la donación de óvulos (hiperestimulación ovárica con desenlace de extirpación de parte del órgano) cuya responsabilidad recae directamente en la paciente, en este caso la denunciante.

La denunciante se sometió el día 19 de marzo de 2003 a una donación de ovocitos en una clínica de Madrid. Tras la intervención tuvo molestias por lo que se puso en contacto con la clínica a la cual acudió el día 20 de marzo en dos ocasiones en las que fue explorada, se le practicó una ecografía y se le realizaron análisis que determinaron que el nivel de coagulación y perfil bioquímico de la recurrente eran normales. La paciente fue diagnosticada con distensión abdominal, pero dijo sentirse mejor, por lo que se le recomendó la ingesta de un litro de bebida isotónica antes de acostarse para evitar la deshidratación, controlar lo que orinaba y reposo, además de regresar al día siguiente para repetir los análisis y la ecografía. La compareciente no apareció el día 21 y no pudo ser localizada por la clínica.

El día 22 de marzo acudió al hospital dónde fue ingresada bajo el diagnóstico de hiperestimulación ovárica y hemorragia peritoneal, por lo que tuvo que practicársele la extirpación parcial del ovario derecho ese mismo día.

Pese a haber sido advertida por parte de la clínica de la importancia de guardar reposo tras su diagnóstico de distensión abdominal, no fue hasta el día 23 de marzo cuando la recurrente pidió la baja de su puesto de trabajo.

Ante la denuncia la defensa destacó que en el consentimiento informado firmado por la denunciante advertía que una de las posibles complicaciones es el SHO, el cual tiene diferentes grados de gravedad siendo el más elevado de ellos muy severo, habiéndole informado también de los posibles síntomas tales como, distensión abdominal, naúseas y vómitos entre otros, destacando el dolor abdominal intenso y dificultad para respirar. Es decir, la recurrente conocía las complicaciones y riesgos de la intervención a la que voluntariamente se sometió.

Es por ello, que no se considera que la hiperestimulación ovárica y la hemorragia peritoneal que padeció fueran consecuencia de una mala praxis, tal como

${ }^{69}$ ROJ: AAP M 6143/2004 - ECLI:ES:AP M:2004:6143a . Ponente: Araceli Perdices López. 
IUS ET SCIENTIA (ISSN 244-8478) 2019, Vol. 5, nº 2, pp. 11-54 LA DONACIÓN DE ÓVULOS EN LA REPRODUCCIÓN ASISTIDA: RIESGOS Y RESPONSABILIDAD. Belén Avilés Alepuz y Francisca Ramón Fernández, Universidad Politécnica de Valencia, beaval@etsiamn.upv.es, frarafer@urb.upv.es Recibido: 17/09/2019. Aceptado: 10/10/2019 DOI: http://doi.org/10.12795/IESTSCIENTIA.2019.i02.03

confirma el médico forense.

La parte recurrente interesó que se tomara declaración a los doctores de la clínica y el hospital en que fue atendida a efectos de determinar si el cuadro clínico que presentaba cuando fue ingresada en el hospital fue consecuencia de haber transcurrido tres días desde la donación de óvulos sin haber sido tratada del SHO que presentó pese a haber acudido anteriormente a la clínica alegando los síntomas que padecía.

Citadas y demostradas las pruebas médicas practicadas sobre la recurrente en la clínica donde se produjo la donación tras exponer su sintomatología, y habiendo sido determinado por la clínica que la susodicha padecía de distensión abdominal y conocidas las recomendaciones que se le dieron, el juez determinó que no había indicios de una actuación médica errónea siendo que la paciente no siguió las recomendaciones recibidas y no acudió a la cita ni fue localizada el día 21 de marzo. Además, se demostró que la recurrente no guardó el reposo aconsejado pues no fue hasta el día 23, cuatro días después de realizada la intervención de donación de óvulos, que la recurrente pidió la baja en su puesto de trabajo.

La Sala decidió desestimar el recurso de apelación interpuesto por la representación procesal de la recurrente contra el auto que ahora queda confirmado.

B) Extracción de ovocitos de una mujer con ovario poliquístico en que se producen complicaciones a causa de su situación médica personal derivando en la extracción de ambas trompas de Falopio y ovarios

Resuelto por SAP Audiencia Provincial Madrid (Sección 14), de 28 de febrero de $2018^{70}$, este auto ha sido seleccionado para este trabajo al basarse la autora para la demanda en la deficiente información aportada a la hora de firmar el consentimiento informado.

En marzo de 2014 la demandante y su esposo, diagnosticados de infertilidad primaria y habiéndose sometido a cuatro ciclos de Inseminación Artificial Homóloga sin éxito, comenzaron un tratamiento de FIV con una clínica de su elección emplazada fuera de la ciudad en la que en ese momento residían, por lo que los controles se realizarían en su ciudad por un ginecólogo elegido por la

${ }^{70}$ ROJ: AAP M 6143/2004. ECLI:ES:AP M:2004:6143a . Ponente: Juan Lucas Uceda Ojeda. 
IUS ET SCIENTIA (ISSN 244-8478) 2019, Vol. 5, nº 2, pp. 11-54 LA DONACIÓN DE ÓVULOS EN LA REPRODUCCIÓN ASISTIDA: RIESGOS Y RESPONSABILIDAD. Belén Avilés Alepuz y Francisca Ramón Fernández, Universidad Politécnica de Valencia, beaval@etsiamn.upv.es, frarafer@urb.upv.es Recibido: 17/09/2019. Aceptado: 10/10/2019 DOI: http://doi.org/10.12795/IESTSCIENTIA.2019.i02.03

pareja siendo mandados los resultados por e- mail a la clínica.

La clínica firmó el documento de autorización para "ser sometida a un procedimiento de inducción de ovulación" sin referirse a riesgos adicionales debido a la edad de la paciente (28 años), a sus antecedentes médicos (sufría de ovario poliquístico), ni al tipo de seguimiento que se iba a realizar (a través de email).

El día 3 de abril se inicia el ciclo de FIV aplicando los fármacos y dosis prescritas al efecto y el 29 de abril se realiza la punción ovárica, obteniéndose 25 ovocitos. No se realizó en ese momento la transferencia embrionaria debido al riesgo de sufrir hiperestimulación ovárica, este procedimiento tuvo lugar en días posteriores. La demandante permanece en la clínica hasta el final del día al sentir dolor, náuseas y mareo.

El día 30 sufre un ingreso hospitalario donde se le diagnóstica SHO Grado III. El día 1 de mayo ante la presencia de signos de anemización se decide realizar una laparotomía exploratoria, que fue seguida de anexectomia bilateral (extirpación de los trompas de Falopio y de los ovarios) ante el cuadro agudo de sangrado activo en ambos ovarios en toda su superficie. Fue dada de alta, tras problemas por dehiscencia de la cicatriz quirúrgica que requirieron nueva cirugía, el día 12 de mayo de 2014.

La demandante denuncia mala praxis contra la clínica responsable de la extracción de ovocitos y codenuncia a las dos doctoras profesionales de dicho centro responsables de su seguimiento, en base a:

a) Que en el consentimiento informado firmado por ella misma para realizar el tratamiento al cual se sometió, no se reflejaron los riesgos reales adaptados a las circunstancias subjetivas de la actora, es decir, la edad y la existencia de ovario poliquístico.

b) La existencia de un error en el tratamiento prescrito el cual la demandante siguió, alegando que en el tratamiento prescrito la administración de hormonas es excesivo.

c) Que el seguimiento únicamente telemático por parte de las doctoras de la clínica no era suficiente al tratarse de una paciente de riesgo como era su caso.

Por los motivos expuestos, la demandante solicitó que se condenase 
IUS ET SCIENTIA (ISSN 244-8478) 2019, Vol. 5, nº 2, pp. 11-54 LA DONACIÓN DE ÓVULOS EN LA REPRODUCCIÓN ASISTIDA: RIESGOS Y RESPONSABILIDAD. Belén Avilés Alepuz y Francisca Ramón Fernández, Universidad Politécnica de Valencia, beaval@etsiamn.upv.es, frarafer@urb.upv.es Recibido: 17/09/2019. Aceptado: 10/10/2019 DOI: http://doi.org/10.12795/IESTSCIENTIA.2019.i02.03

solidariamente a la clínica y a las doctoras que llevaban su seguimiento telemático al pago de la suma de 95.053,33 euros más intereses legales.

La sentencia de instancia no estimó la demanda condenando a los actores al pago de las costas procesales.

Contra esta resolución interpone la demandante un recurso de apelación basándose en:

a) La ausencia de negligencia médica durante la intervención no exime a las demandadas de culpa dado que, como ha afirmado el TS en numerosos casos, la falta de información adecuada constituye en sí una negligencia que atenta contra la libertad del paciente

b) La falta de información adecuada y adaptada a su situación a la hora de obtener el consentimiento informado. La demandante invoca el Artículo 10.1 c) de la Ley 41/2002, el cual recoge que el facultativo debe informar entre otros de los riesgos relacionados con las circunstancias personales del paciente previamente a recabar el consentimiento informado. Basándose en esta ley, los actores denunciaron la falta de información pues no conocían que las condiciones de la paciente, con 28 años y ovario poliquístico, agravaban la posibilidad de sufrir síndrome de hiperestimulación ovárica, el cual, según los actores, se produjo y finalmente desencadenó la situación que llevó a la extirpación de los ovarios.

La Audiencia determinó, en primer lugar, que fue un hemoperitoneo, y no el SHO, lo que provocó la situación que hizo necesaria la intervención quirúrgica y la extirpación de los ovarios de la demandante analizados los informes periciales.

En segundo lugar, estimó que, tal y como prevé el Tribunal Supremo, en sentencia. de 29 de junio de $2007^{71}$, y sentencia de 8 de abril de $2016^{72}$, en cuanto a los criterios para fijar la indemnización correcta cuando no se ha dado una información adecuada al paciente, ha de distinguirse entre supuestos en los que, de haberse proporcionado la información previa adecuada, la decisión del paciente no hubiese variado y, por ello, no habría lugar a indemnización y aquellos en los que, de haber existido información previa adecuada, la decisión del paciente hubiese sido negarse a la intervención, caso en el cual cabría indemnización íntegra del prejuicio que se ha materializado.

\footnotetext{
${ }^{71}$ ROJ: STS 4472/2007, ECLI:ES:TS:2007:4472. Ponente: José Antonio Seijas Quintana.

${ }^{72}$ ROJ: STS 1427/2016, ECLI:ES:TS:2016:1427. Ponente: Eduardo Baena Ruiz.
} 
IUS ET SCIENTIA (ISSN 244-8478) 2019, Vol. 5, nº 2, pp. 11-54 LA DONACIÓN DE ÓVULOS EN LA REPRODUCCIÓN ASISTIDA: RIESGOS Y RESPONSABILIDAD. Belén Avilés Alepuz y Francisca Ramón Fernández, Universidad Politécnica de Valencia, beaval@etsiamn.upv.es, frarafer@urb.upv.es Recibido: 17/09/2019. Aceptado: 10/10/2019 DOI: http://doi.org/10.12795/IESTSCIENTIA.2019.i02.03

Surge la llamada pérdida de oportunidad cuando el daño que exige responsabilidad resulta de haberse omitido información y se produce finalmente el riesgo previsible de la intervención, se considera que se ha privado al paciente de la toma de decisiones que afectan a su salud resultado de dicha falta de información, tal y como indican las SSTS de 10 de mayo de $2006,{ }^{73}$ y de 8 de abril de $2016 .^{74}$

Las doctoras codemandadas declaran en este sentido que la paciente ya no podía gestar antes de realizada la intervención y que los problemas derivados de la ausencia de ovarios son actualmente tratables con fármacos sin secuelas.

Por ello, la Audiencia desestimó el recurso de apelación interpuesto por la demandante.

C) Donación de óvulos en que se produce infección por inoculación accidental derivado de la punción resultando en una salpingectomía bilateral

Se pronuncio sobre ello la AP de Barcelona (Sección 13), en sentencia del 6 de mayo de $2019^{75}$ y resulta de interés en el presente trabajo al tratarse por un lado la negligencia médica en relación al correcto desarrollo de las prácticas médicas, desestimado por la sala, y la falta de adecuada información en los supuestos de cirugía voluntaria, causante también de negligencia médica, razón por la cual la Sala condena a los demandados por las razones que se expondrán a continuación. La demandante se sometió a la punción ovárica transvaginal para la donación de ovocitos el día 9 de abril de 2011, cursando el postoperatorio sin incidencias y siendo dada de alta. Acudió el día 20 de abril al servicio de urgencias del hospital en el que se le practicó la intervención presentando fiebre de dos días de evolución y dolor abdominal. La demandante fue hospitalizada el día 20 al diagnosticársele infección por estafilococo aureus coagulasa negativo (ECN), bacteria no hospitalaria residente en la piel y mucosas humanas como la vagina. El origen de la infección es por inoculación accidental al practicársele la punción en el fondo del saco vaginal, arrastrando el germen que produjo la infección.

El tratamiento recibido fue con antibióticos endovenosos, previo cultivo vaginal y hemocultivo que confirmó la infección y cepa bacteriana. Se practicó un TAC en

\footnotetext{
${ }^{73}$ ROJ: STS 3027/2006, ECLI:ES:TS:2006:3027. Ponente: José Antonio Seijas Quintana.

${ }^{74}$ ROJ: STS 1427/2016, ECLI:ES:TS:2016:1427. Ponente: Eduardo Baena Ruiz.

${ }^{75}$ ROJ: SAP B 4668/2019, ECLI:ES:APB:2019:4668. Ponente: Fernando Utrillas Carbonell.
} 
IUS ET SCIENTIA (ISSN 244-8478) 2019, Vol. 5, nº 2, pp. 11-54 LA DONACIÓN DE ÓVULOS EN LA REPRODUCCIÓN ASISTIDA: RIESGOS Y RESPONSABILIDAD. Belén Avilés Alepuz y Francisca Ramón Fernández, Universidad Politécnica de Valencia, beaval@etsiamn.upv.es, frarafer@urb.upv.es Recibido: 17/09/2019. Aceptado: 10/10/2019 DOI: http://doi.org/10.12795/IESTSCIENTIA.2019.i02.03

el que se apreció salpingitis bilateral, por lo que el día 23 de abril de 2011 se practicó una laparoscopia quirúrgica y laparotomía, practicándose la salpingectomía bilateral o extirpación de las trompas de Falopio.

El 5 de mayo se practicó una nueva laparoscopia exploradora. El postoperatorio ocurrió sin incidencias, la paciente y demandante fue finalmente dada de alta 20 días después de su ingreso hospitalario, el día 10 de mayo de 2011.

La recurrente interpuso una demanda reclamando responsabilidad civil por negligencia médica contra tres médicos del centro hospitalario en que fue atendida, el mismo hospital y dos compañías aseguradoras por los daños y perjuicios soportados a consecuencia de la infección sufrida, alegando falta de diligencia en el acto quirúrgico, falta de diligencia en la detección de la infección, falta de diligencia en la aplicación del tratamiento adecuado y aplicación de la doctrina del daño desproporcionado, reclamando una indemnización de 184.371'86 euros.

El juez desestimó íntegramente la demanda formulada por la representación procesal de la demandante, razón por la cual la misma interpuso un recurso de apelación.

El juez determinó con respecto a la pretendida actuación negligente que no existían pruebas que demostrasen la inadecuación de la técnica empleada, contravención del protocolo habitual para evitar infecciones por omisión de limpieza antiséptica de la zona de intervención quirúrgica, de las agujas o cualquier material sanitario o cualquier otra actuación negligente causa de la infección. Máxime cuando la infección fue causa por ECN, colonizador del ser humano y para el cual no existe en virtud del estado actual de la ciencia médica medio para prevenir y evitar por completo la infección por dicho agente, siendo este un riesgo poco frecuente y excepcional pero inevitable en cualquier intervención quirúrgica. Considera la Sala, por tanto, que no es posible establecer la responsabilidad de la demandada al faltar el requisito de la actuación negligente en la ejecución del acto quirúrgico.

En cuanto a la pretendida falta de diligencia en la detección de la infección y la pretendida falta de diligencia en la aplicación del tratamiento adecuado, dada la naturaleza de la infección (que no presenta síntomas trascurridos varios días de la 
IUS ET SCIENTIA (ISSN 244-8478) 2019, Vol. 5, nº 2, pp. 11-54 LA DONACIÓN DE ÓVULOS EN LA REPRODUCCIÓN ASISTIDA: RIESGOS Y RESPONSABILIDAD. Belén Avilés Alepuz y Francisca Ramón Fernández, Universidad Politécnica de Valencia, beaval@etsiamn.upv.es, frarafer@urb.upv.es Recibido: 17/09/2019. Aceptado: 10/10/2019 DOI: http://doi.org/10.12795/IESTSCIENTIA.2019.i02.03

infección) y considerada la actuación médica (las pruebas realizadas para discernir el diagnóstico y el tratamiento con antibióticos seguido), determina el juez que no es posible alcanzar la conclusión probatoria de pretendida existencia de negligencia por error en diagnóstico o falta de diligencia en la aplicación del tratamiento.

Por último, en cuanto a la aplicación de la doctrina del daño desproporcionado invocada por la apelante, este es el "daño médico desproporcionado no previsto ni explicable en la esfera de la actuación profesional", ${ }^{76}$ y exige del médico una explicación coherente acerca de la importante disonancia producida entre el riesgo inicial y la consecuencia producida. ${ }^{77}$

Existe en el presente caso un resultado desproporcionado entre la actividad médica inicial y el resultado producido, pero no se puede apreciar responsabilidad civil en aplicación de la mencionada doctrina ya que no se ha demostrado la existencia de negligencia médica en la punción ovárica y seguimiento posterior y existe una justificación médica de la actuación desarrollada, en el diagnóstico y el tratamiento, excluyendo la aplicabilidad de las consecuencias de la doctrina del daño desproporcionado.

El estudio de la sentencia resulta de interés hasta este punto dado que materializa uno de los posibles, aunque de baja incidencia, riesgos mencionados asociados a la donación de óvulos y nos permite conocer la respuesta jurídica en cuanto a la responsabilidad por el daño en estos casos.

Cabe destacar, sin embargo, por su relevancia, la segunda parte del recurso de apelación en el cual la demandante apela a la ausencia de consentimiento informado en relación con la intervención quirúrgica consistente en la punción ovárica transvaginal.

El ponente enfatiza la importancia del consentimiento informado como elemento esencial de la lex artis, debiendo esta información adecuarse a las capacidades y situación personal de cada paciente, además de hacer distinción entre los supuestos de intervención por existir una patología previa y aquellos de carácter

${ }^{76}$ STS de 23 de mayo de 2007, ROJ: STS 3412/2007, ECLI:ES:TS:2007:3412, Vicente Luis Montés

Penadés.

${ }^{77}$ STS de 16 de abril de 2007, ROJ: STS 2676/2007 - ECLI:ES:TS:2007:2676, Ponente: Vicente Luis Montés Penadés. 
IUS ET SCIENTIA (ISSN 244-8478) 2019, Vol. 5, nº 2, pp. 11-54 LA DONACIÓN DE ÓVULOS EN LA REPRODUCCIÓN ASISTIDA: RIESGOS Y RESPONSABILIDAD. Belén Avilés Alepuz y Francisca Ramón Fernández, Universidad Politécnica de Valencia, beaval@etsiamn.upv.es, frarafer@urb.upv.es Recibido: 17/09/2019. Aceptado: 10/10/2019 DOI: http://doi.org/10.12795/IESTSCIENTIA.2019.i02.03

voluntario.

Concluye la Sala que teniendo en cuenta el carácter voluntario de la intervención cuyo objeto es la donación de óvulos y la clasificación de la punción ovárica como procedimiento invasor, la exigencia de información acerca de los riesgos era mayor que en un supuesto de medicina realizada para la curación del paciente, como fue la segunda intervención quirúrgica para remediar la infección sufrida por la paciente.

Atendiendo a que se practicó la intervención quirúrgica sin que la demandada dispusiese del consentimiento informado firmado por la demandante (sí disponía, sin embargo, del consentimiento informado para la anestesia) y siendo imposible alcanzar por tanto, la conclusión probatoria de que la demandante hubiera sido debidamente informada, concluye el ponente que existe en este caso mala praxis médica en la parte demandada. Pues tratándose de medicina voluntaria, la demandante podría no haber prestado su consentimiento en el supuesto de haber sido informada del riesgo de infección, con pérdida de las dos trompas de Falopio, habiendo evidencias causales entre el acto médico y el daño, por lo que la indemnización debe abarcar todo el perjuicio corporal sufrido.

La demandante sufrió 20 días de ingreso hospitalario, la estabilización de los daños corporales se produjo noventa días después del alta hospitalaria, siendo impeditivos de su ocupación habitual. Además, la pérdida de las trompas de Falopio le obliga a recurrir a técnicas de reproducción asistida en caso de querer gestar en un futuro. Fue diagnosticada de trastorno de ansiedad y depresión, desarrollado a partir de las complicaciones derivadas de la punción, con pauta menor de medicación psicofármacos y psicoterapia. Existen también cicatrices por debajo del ombligo. Los demandados fueron condenados a la indemnización de la demandante con 63.116'10 euros.

D) Extracción de ovocitos para posterior tratamiento de TRHA con resultado de SHO y Tromboembolismo pulmonar subsegmentario

Resuelto por STS, Sala de lo Contencioso, Madrid (Sección 8), de 18 de mayo de $2007 .^{78}$

La demandante se sometió a un procedimiento de extracción de ovocitos en un

78 ROJ: STSJ M 9149/2007, ECLI:ES:TSJM:2007:9149. Ponente: Ángel Francisco SuárezBárcena Morillo-Velarde. 
IUS ET SCIENTIA (ISSN 244-8478) 2019, Vol. 5, nº 2, pp. 11-54 LA DONACIÓN DE ÓVULOS EN LA REPRODUCCIÓN ASISTIDA: RIESGOS Y RESPONSABILIDAD. Belén Avilés Alepuz y Francisca Ramón Fernández, Universidad Politécnica de Valencia, beaval@etsiamn.upv.es, frarafer@urb.upv.es Recibido: 17/09/2019. Aceptado: 10/10/2019 DOI: http://doi.org/10.12795/IESTSCIENTIA.2019.i02.03

Hospital tras haber sido diagnosticada de infertilidad sin conocerse la causa específica de la disfunción. Tras la hiperestimulación ovárica se produjo la punción ovárica que debido a complicaciones sin especificar a la paciente, se prolongó más de 10 horas siendo lo habitual 2 horas. Ocho días después acudió al hospital aquejada de fortísimos dolores de pecho que le impedían respirar, determinándose la causa de una embolia pulmonar. La paciente fue diagnosticada de SHO y Tromboembolismo pulmonar subsegmentario, pruebas posteriores confirmaron que la paciente sufría de Síndrome de Antifosfolípido Primario.

La demandante reclama por los daños sufridos contra la administración sanitaria, el Tribunal de lo Contencioso-Administrativo desestima su petición.

E) Donación de óvulos con resultado de SHO con cura sin secuelas

Resuelto por SAP de Granada (Sección2), de 14 de octubre de $2011 .^{79} \mathrm{La}$ denunciante sufre SHO tras someterse a donación de óvulos. El Juzgado de Instrucción dictó sobreseimiento provisional al no apreciar negligencia médica alguna por poseer el Centro del consentimiento informado firmado por la donante, en el cual quedaban definidas las complicaciones típicas del proceso médico.

F) Donación de óvulos con resultado de lesiones

Resuelto por SAP de Madrid (Sección 30), de 4 de diciembre de $2017 .^{80} \mathrm{La}$ denunciante fue intervenida para una donación de óvulos produciéndose complicaciones que requirieron intervención quirúrgica. Las lesiones tardaron en sanar 168 días de los cuales 52 días fueron impeditivos para sus ocupaciones habituales.

Tres dictámenes médicos se pronunciaron con objeto de discernir si las lesiones sufridas fueron o no causadas por una negligencia médica. Dada la disparidad de las declaraciones de los expertos se produjo el sobreseimiento provisional de las actuaciones.

Las seis sentencias descritas han de servir a modo de ejemplificación de la realidad actual de la extracción de ovocitos en nuestro país. Estas resoluciones han sido solamente algunas de las muchas que han resuelto distintos casos respecto del tema que nos ocupa, demostrando que, aunque las complicaciones derivadas de la extracción de ovocitos, para uso propio o donación, son consideradas de baja

${ }^{79}$ ROJ: AAP GR 335/2011, ECLI:ES:APGR:2011:335A. Ponente: Pedro Ramos Almenara.

${ }^{80}$ ROJ: AAP M 5413/2017, ECLI: ES:APM:2017:5413A. Ponente: María Pilar Oliván Lacasta. 
IUS ET SCIENTIA (ISSN 244-8478) 2019, Vol. 5, nº 2, pp. 11-54 LA DONACIÓN DE ÓVULOS EN LA REPRODUCCIÓN ASISTIDA: RIESGOS Y RESPONSABILIDAD. Belén Avilés Alepuz y Francisca Ramón Fernández, Universidad Politécnica de Valencia, beaval@etsiamn.upv.es, frarafer@urb.upv.es Recibido: 17/09/2019. Aceptado: 10/10/2019 DOI: http://doi.org/10.12795/IESTSCIENTIA.2019.i02.03

frecuencia y habitualmente resuelven sin complicaciones a largo plazo, estas se materializan siendo en algunos casos de elevada gravedad.

Destacar también lo reciente de algunas de las resoluciones a fin de recalcar que, pese a que tanto las técnicas como los conocimientos médicos y medidas de seguridad avanzan a pasos agigantados en el ámbito de las TRHA, las lesiones derivadas de estas son una realidad que han de tener en cuenta tanto los Centros como las mujeres que deciden someterse a ellas.

\section{CONCLUSIONES}

Aunque tanto el acto de donar óvulos como el de recurrir a la reproducción asistida con la finalidad de ser padres se nos antoje una situación habitual en nuestro país sobre la cual posiblemente no muchos hayan reflexionado, que haya debate en este aspecto es tan innegable como que en países como Italia o Alemania la ovodonación no está permitida.

La negativa legislativa de algunos países a la ovodonacion, sumado a la amplia permisibilidad y bajo coste de estas terapias en nuestro país (en comparación con los países vecinos europeos), ha convertido a España en destino de ciudadanos europeos que desean someterse a alguna TRHA, predominando italianos y alemanes o franceses y ciudadanos de Reino Unido cuya legislación es más restrictiva en el uso de dichas técnicas.

La donación queda definida por nuestra jurisdicción como un acto anónimo en el que se preserva salvo circunstancias extraordinarias, la identidad de las donantes. Existe al respecto un debate, no solamente en España, en cuanto al derecho de los niños nacidos de material biológico de donantes, ya sea esperma y/u óvulos, de conocer su origen genético. Este es un problema ético y social por lo que cualquiera fuese la respuesta del legislador a este respecto, no satisfaría a todo el mundo. Por esta razón, países como Dinamarca contemplan en su normativa la coexistencia de la donación de gametos de forma anónima o no anónima, pudiendo el donante escoger. Sin embargo, en España la donación se contempla desde la primera legislación del año 1988 hasta la actual como un acto anónimo.

Otro motivo de controversia en el tema que nos ocupa es la obligación de algunos 
IUS ET SCIENTIA (ISSN 244-8478) 2019, Vol. 5, nº 2, pp. 11-54 LA DONACIÓN DE ÓVULOS EN LA REPRODUCCIÓN ASISTIDA: RIESGOS Y RESPONSABILIDAD. Belén Avilés Alepuz y Francisca Ramón Fernández, Universidad Politécnica de Valencia, beaval@etsiamn.upv.es, frarafer@urb.upv.es Recibido: 17/09/2019. Aceptado: 10/10/2019 DOI: http://doi.org/10.12795/IESTSCIENTIA.2019.i02.03

países, entre los que se encuentra España, de ofrecer una compensación económica fijada por el Ministerio de Sanidad, Consumo y Bienestar Social por las molestias ocasionadas por el proceso de extracción de ovocitos. Aunque la compensación económica sea contemplada por la Ley 14/2006 Artículo 5.3 únicamente como una forma de resarcir las molestias físicas y los gastos laborales y de desplazamiento, puede suponer un aliciente para muchas mujeres que se encuentren en situaciones económicas apuradas.

Se ha comentado la desinformación que sufren en algunos casos las donantes que acuden a las Clínicas privadas en cuanto a los riesgos que asumen en dicho acto, así como la importancia que otorga el tribunal al consentimiento informado en estos casos de "medicina voluntaria". También ha sido expuesta la dificultad de atribuir de manera inequívoca ciertos resultados a este procedimiento, dado que la medicina no es una ciencia exacta y esta varía en función del protocolo empleado y el profesional que lo lleva a cabo.

Es difícil determinar las consecuencias a largo plazo de llevar a cabo la donación en España ya que no es posible realizar un estudio retrospectivo por el carácter siempre anónimo de la donación. Además, no fue hasta 2017 cuando se puso en marcha el Sistema de Información en Reproducción Humana Asistida mediante el cual se crea el Registro de Donantes de Gametos y Preembriones. La creación de dicho registro fue por primera vez dispuesto en la Ley 35/1988 en la Disposición Final Tercera otorgando un año de plazo para su formación y de nuevo invocado en la renovada Ley 14/2006 en el Artículo 21.3, que determinaba de nuevo la creación de dicho registro.

A causa de la inexistencia de dicho registro, no existía manera objetiva por parte de las Clínicas de determinar el número de donaciones que había realizado con anterioridad un futuro donante si la donación había tenido lugar en otro centro. Es por ello, que el Artículo 5.7 de la Ley 14/2006 que determina un máximo de seis hijos nacidos a partir de gametos de un mismo donante puede haber sido desoído en múltiples ocasiones, sin forma de determinarlo.

Por todo ello, es importante que el recién instaurado Registro de Donantes y Preembriones funcione de acuerdo a lo estipulado por la Ley, abarcando información relativa a la identidad de los donantes, aunque esta solo se haga 
IUS ET SCIENTIA (ISSN 244-8478) 2019, Vol. 5, nº 2, pp. 11-54 LA DONACIÓN DE ÓVULOS EN LA

REPRODUCCIÓN ASISTIDA: RIESGOS Y RESPONSABILIDAD. Belén Avilés Alepuz y Francisca

Ramón Fernández, Universidad Politécnica de Valencia, beaval@etsiamn.upv.es, frarafer@urb.upv.es

Recibido: 17/09/2019. Aceptado: 10/10/2019 DOI: http://doi.org/10.12795/IESTSCIENTIA.2019.102.03

pública en casos de extrema necesidad, así como información relativa a las técnicas empleadas y su tasa de éxito, con el fin de conocer los beneficios e inconvenientes de cada una de ellas.

En definitiva, tanto el uso de TRHA como la donación de óvulos son prácticas actualmente comunes en nuestro país pese a las implicaciones morales y éticas que sustentan. Es por ello, que la legislación ha de adaptarse al incesante avance de la investigación médica y a la realidad social, determinando las condiciones bajo las cuales se pueden llevar a cabo estas técnicas y la donación de gametos y garantizándose la información cuando no es posible garantizar la seguridad.

\section{BIBLIOGRAFÍA}

AL-AZEMI, M., LÓPEZ BERNAL, A., STEELE, J., GRAMSBERGEN, I., BARLOW, D. Y KENNEDY S., "Ovarian response to repeated controlled stimulation in in-vitro fertilization cycles in patients with ovarian endometriosis", Human Reproduction, 15(1), 2000, pp. 72-75. Disponible en: https://academic.oup.com/humrep/article/15/1/72/702024 (Consultado el 25 de julio de 2019).

APARICIO RODRÍGUEZ, I., Papel de la hormona anti-mülleriana en el manejo de la reserva ovárica en reproducción asistida, Tesis doctoral, ORDÁS SANTO TOMÁS, J. y CUADRADO MANGAS, M. C. (dir.), Universidad Autónoma de Madrid. $2009 . \quad$ Madrid, en: https://repositorio.uam.es/bitstream/handle/10486/748/20275_aparicio_rodriguez iria.pdf?sequence=1\&isAllowed=y (Consultado el 26 de julio de 2019).

BODRI, D., GUILlÉN, J., POlO, A., TRULlENQUE, M., ESTEVE, C. y COLL, O., "Complications related to ovarian stimulation and oocyte retrieval in 4052 oocyte donor cycles", Reproductive biomedicine online, 17(2), 2008, pp. 237-243. Disponible en: https://www.rbmojournal.com/article/S14726483(10)60200-3/pdf (Consultado el 25 de julio de 2019).

BROEKMANS, F. J., VISSER, J. A., LAVEN, J. S., BROER, S. L., THEMMEN, A. P., y FAUSER, B. C., “Anti-Müllerian hormone and ovarian dysfunction”. Trends in Endocrinology \& Metabolism, 19(9), 2008, pp. 340-347. 
IUS ET SCIENTIA (ISSN 244-8478) 2019, Vol. 5, nº 2, pp. 11-54 LA DONACIÓN DE ÓVULOS EN LA REPRODUCCIÓN ASISTIDA: RIESGOS Y RESPONSABILIDAD. Belén Avilés Alepuz y Francisca Ramón Fernández, Universidad Politécnica de Valencia, beaval @etsiamn.upv.es, frarafer@urb.upv.es Recibido: 17/09/2019. Aceptado: 10/10/2019 DOI: http://doi.org/10.12795/IESTSCIENTIA.2019.i02.03

CAligara, C., NAVArRo, J., VARGAS, G., Simón, C., PEllicer, A., REMOHÍ, J., "The effect of repeated controlled ovarian stimulation in donors", Human Reproduction, 16(11), 2001, pp. 2320- 2323.

COMISIÓN NACIONAL DE REPRODUCCIÓN HUMANA ASISTIDA, Aspectos clínicos específicos de los donantes de ovocitos. Disponible en: http://www.cnrha.mscbs.gob.es/registros/donantes/aspectosClinicos/ovocitos/hom e.htm (Consultado el 23 de mayo de 2019).

CRAVIOTTO VALLE, P., "Embriones en reproducción humana asistida: controversias sobre la congelación y el estudio genético pre-implantatorio", Revista electrónica IUS ET SCIENTIA, vol. 5, no. 1, 2019, pp. 54-89. Disponible en: $\quad$ https://institucional.us.es/iusetscientia/index.php/ies/article/view/165/118 (Consultado el 27 de julio de 2019).

DÍAZ MARTÍNEZ, A., "Responsabilidad por daños en la aplicación de técnicas de reproducción asistida: diferencias con la investigación biomédica (a propósito de las SSTS de 23 de octubre de 2008 y 20 de noviembre de 2009)", Revista de derecho y genoma humano: genética, biotecnología y medicina avanzada. (32), 2010, pp. 193-218. Disponible en: https://mega.nz/\#!SdklEBLR!c0NSYS4e611GFkqxhWGgLGPoZagJkgR_LUk30f5gNlA (Consultado el 27 de julio de 2019).

DOLZ, M., DÍAZ-GARCÍA DONATO, J., MARTIN, V., MORENO, X., BENAVENT, M., GIJÓN, L. y PONS, J., "Protocolo con antagonistas de la GnRH y maduración final con bolo de agonista en un programa de donación de ovocitos", Revista Iberoamericana de Fertilidad, 24(4), 2006, pp. 245- 250. Disponible en: https://docplayer.es/11501077-Protocolo-con-antagonistas-de-lagnrh-y-maduracion-final-con-bolo-de-agonista-en-un-programa-de-donacion-deovocitos.html (Consultado el 25 de julio de 2019).

FECUNDACIÓN IN VITRO VALENCIA, Donación de óvulos. Disponible en: https://www.fiv-valencia.es/donar-ovulos-valencia/\#gref (Consultado el 9 de mayo de 2019).

FERNÁNDEZ-SAMBRUNO CLAVER, G. J. (2018). La responsabilidad penal por mala praxis Médica. Tesis de máster, BALBUENA PÉREZ, D. E. (dir.), https://reunir.unir.net/bitstream/handle/123456789/6389/FERNANDEZ- 
IUS ET SCIENTIA (ISSN 244-8478) 2019, Vol. 5, nº 2, pp. 11-54 LA DONACIÓN DE ÓVULOS EN LA REPRODUCCIÓN ASISTIDA: RIESGOS Y RESPONSABILIDAD. Belén Avilés Alepuz y Francisca Ramón Fernández, Universidad Politécnica de Valencia, beaval@etsiamn.upv.es, frarafer@urb.upv.es Recibido: 17/09/2019. Aceptado: 10/10/2019 DOI: http://doi.org/10.12795/IESTSCIENTIA.2019.i02.03

SAMBRUNO\%20CLAVER\%20GONZALO\%20JUAN.pdf?sequence=1\&isAllo wed $=y$ (Consultado el 27 de julio de 20019).

FRÍAS INIESTA, J., “¿Hay diferencias entre las gonadotropinas disponibles para la estimulación ovárica en técnicas de reproducción asistida?”, Progresos de obstetricia y ginecología. Revista oficial de la Sociedad Española de Ginecología y Obstetricia, 51(5), 2008, pp. 281-300.

GARCÍA, E. (2013). "El «negocio» de donar óvulos y semen”, Levante-EMV, 10 de junio de 2013. Disponible en: https://www.levante-

emv.com/sociedad/2013/05/03/negocio-donar-ovulos-semen/994802.html

(Consultado el 10 de mayo de 2019).

INSTITUTO VALENCIANO DE INFERTILIDAD, Donación de óvulos: todo lo que necesitas saber. Disponible en: https://ivi.es/blog/donacion-de- ovulos-todolo-que-necesitas-saber/ (Consultado el 9 de mayo de 2019).

KWEE J., BROEKMANS F.J., HENDRIKS D.J., MOL, B.W. y LAMBALK, C.B., "A systematic review of tests predicting ovarian reserve and IVF outcome". Human Reproduction Update, 12(6), 2006, pp. 685-718. Disponible en: https://pdfs.semanticscholar.org/a1f0/e8629371e9b60bfd67fce4e791dc8dea50cf.p df?_ga=2.163550716.135265663.1564251597-898571686.1562517395

(Consultado el 24 de julio de 2019).

JAYAPRAKASAN, K., HERBERT, M., MOODY, E., STEWART, J.A. Y MURDOCH, A.P., "Estimating the risks of ovarian hyperstimulation syndrome (OHSS): implications for egg donation for research", Human Fertility, 10(3), 2007, pp. 183-187. Disponible en: https://www.researchgate.net/profile/Kannamannadiar_Jayaprakasan/publication/ 6053198 Estimating the risks of ovarian hyperstimulation syndrome OHSS I mplications_for_egg_donation_for_research/links/02e7e528e5d41acee2000000/E stimating-the-risks-of-ovarian-hyperstimulation-syndrome-OHSS-Implicationsfor-egg-donation-for-research.pdf (Consultado el 26 de julio de 2019).

JENSEN, A., SHARIF, H., FREDERIKSEN, K. y KJAER, S.K., "Use of fertility drugs and risk of ovarian cancer: Danish Population Based Cohort Study", BMJ, 2009;338:b249. Disponible en: https://www.bmj.com/content/338/bmj.b249 (Consultado el 24 de julio de 2019). 
IUS ET SCIENTIA (ISSN 244-8478) 2019, Vol. 5, nº 2, pp. 11-54 LA DONACIÓN DE ÓVULOS EN LA REPRODUCCIÓN ASISTIDA: RIESGOS Y RESPONSABILIDAD. Belén Avilés Alepuz y Francisca Ramón Fernández, Universidad Politécnica de Valencia, beaval @etsiamn.upv.es, frarafer@urb.upv.es Recibido: 17/09/2019. Aceptado: 10/10/2019 DOI: http://doi.org/10.12795/IESTSCIENTIA.2019.i02.03

RODRÍGUEZ JORDÁN, M., Mala Praxis Médica: Responsabilidad penal, civil y administrativa, Ediciones Ciudad Argentina, Buenos Aires, 1999.

JUÁREZ, K., LARA, R. y GARCÍA, J., "Insuficiencia ovárica prematura: una revisión”, Revista chilena de obstetricia y ginecología, 77(2), 2012, pp.148-153. Disponible en: https://scielo.conicyt.cl/pdf/rchog/v77n2/art12.pdf (Consultado el 26 de julio de 2019).

KRAMER, W., SCHNEIDER, J. y SCHULTZ, N., "US oocyte donors: a retrospective study of medical and psychosocial issues", Human reproduction, 24(12), 2009, pp. 3144-3149. Disponible en: https://www.researchgate.net/publication/26788590_US_oocyte_donors_A_retros pective study of medical and psychosocial issues (Consultado el 25 de julio de 2019).

LA MARCA, A. y SUNKARA, S.K., "Individualization of controlled ovarian stimulation in IVF using ovarian reserve markers: from theory to practice", Human Reproduction Update, 20(1), 2014, pp. 124-140. Disponible en: https://www.researchgate.net/publication/257206176_Individualization_of_contro lled ovarian stimulation in IVF using ovarian reserve markers From theory to_practice (Consultado el 25 de julio de 2019).

LÓPEZ y LÓPEZ, A., VALPUESTA FERNÁNDEZ, M. R. y SERRANO FERNÁNDEZ, M., Tratado jurisprudencial de responsabilidad por daños, Tirant lo Blanch, Valencia, 2013.

LUCÍA, C., y NÚÑEZ, R., 'Revisión del perfil sociodemográfico de una muestra local de donantes de gametos, en España: motivación para la donación, procedencia de los donantes, ocupación”, Medicina Reproductiva y Embriología Clínica, 2(1), 2015, pp. 23-30.

NELSON, S.M., YATES, R.W., LYALL, H., JAMIESON, M., TRAYNOR, I., GAudoin, M., MitChell, P., AMBrose, P., y FlEMING, R., "AntiMüllerian hormone-based approach to controlled ovarian stimulation for assisted conception", Human Reproduction, 24(4), 2009, pp. 867-875.

OFICINA EUROPEA DE ESTADÍSTICA EUROSTAT, Evolución de la edad media al primer hijo 1981-2013 en España. Disponible en: https://ec.europa.eu/eurostat/statistics- 
IUS ET SCIENTIA (ISSN 244-8478) 2019, Vol. 5, nº 2, pp. 11-54 LA DONACIÓN DE ÓVULOS EN LA REPRODUCCIÓN ASISTIDA: RIESGOS Y RESPONSABILIDAD. Belén Avilés Alepuz y Francisca Ramón Fernández, Universidad Politécnica de Valencia, beaval@etsiamn.upv.es, frarafer@urb.upv.es Recibido: 17/09/2019. Aceptado: 10/10/2019 DOI: http://doi.org/10.12795/IESTSCIENTIA.2019.i02.03

explained/index.php?title=File:Evolución_de_la_edad_media_al_primer_hijo_19 81-2013_en_España.png (Consultado el 10 de mayo de 2019).

PORTERO LAZCANO, P., "Responsabilidad penal culposa del médico: fundamentos para el establecimiento de la negligencia o impericia", Revista Latinoamericana de Derecho Médico y Medicina Legal, 6(2), 2001, pp. 89-96. Disponible en: https://docplayer.es/4689531-Responsabilidad-penal-culposa-delmedico-fundamentos-para-el-establecimiento-de-la-negligencia-o-impericia.html (Consultado el 27 de julio de 2019).

ROBLES CORCHADO, A., Ensayo clínico, prospectivo, aleatorizado y comparativo, para determinar la eficacia y seguridad de dos protocolos para hiperestimulación ovárica controlada en mujeres que van a ser tratadas con inseminación artificial y que han sido diagnosticadas de esterilidad de origen desconocido, Tesis doctoral, CARRERAS COLLADO, R., y CHECA VIZCAINO, M. A. (dir.), Universidad Autónoma de Barcelona, Barcelona, 2014. Disponible en: https://ddd.uab.cat/pub/tesis/2014/hdl_10803_283948/arc1de1.pdf (Consultado el 27 de julio de 2019).

RODRÍGUEZ ZURRO, L. (2016). Donación de ovocitos en reproducción humana asistida. Cuidados de Enfermería, Trabajo de fin de grado, VELÁZQUEZ BARBADO, M. R. y DEL PINO ORTEGA, M. C. (dir.), Universidad de Valladolid, $\quad 2016 . \quad$ Dalladolid, en: http://uvadoc.uva.es/bitstream/handle/10324/18044/TFG-

H510.pdf? sequence=1\&isAllowed=y (Consultado el 27 de julio de 2019).

RUIZ SÁENZ, A., "El contrato de donación de gametos y preembriones en la legislación española sobre técnicas de reproducción humana asistida", Cuadernos Ibero-Americanos de Derecho Sanitario, 2(2), 2013, pp. 786-801. Disponible en: https://www.researchgate.net/publication/290147543_El_contrato_de_donacion_d e gametos y preembriones en la legislacion espanola sobre tecnicas de repr oduccion_humana_asistida (Consultado el 26 de julio de 2019).

SAUER, M. V., "Defining the incidence of serious complications experienced by oocyte donors: a review of 1000 cases”, American journal of obstetrics and gynecology, 184(3), 2001, pp. 277-278.

SAUER, M. V. y PAULSON, R. J., "Mishaps and misfortunes: complications that 
IUS ET SCIENTIA (ISSN 244-8478) 2019, Vol. 5, nº 2, pp. 11-54 LA DONACIÓN DE ÓVULOS EN LA REPRODUCCIÓN ASISTIDA: RIESGOS Y RESPONSABILIDAD. Belén Avilés Alepuz y Francisca Ramón Fernández, Universidad Politécnica de Valencia, beaval @etsiamn.upv.es, frarafer@urb.upv.es Recibido: 17/09/2019. Aceptado: 10/10/2019 DOI: http://doi.org/10.12795/IESTSCIENTIA.2019.i02.03

occur in oocyte donation", Fertility and sterility, 61(5), 1994, pp. 963-965. Disponible en: https://www.fertstert.org/article/S0015-0282(16)56713-2/pdf (Consultado el 27 de julio de 2019).

SERRA RODRÍGUEZ, A., "El contrato de servicios médicos y la lex artis: Comentario a la STS 2 octubre 1997 (RJ 1997, 7405)", Revista Aranzadi de derecho patrimonial, (1), 1998, pp. 167-174.

SCHNEIDER, J., LAHL, J. y KRAMER, W., "Long-term breast cancer risk following ovarian stimulation in young egg donors: a call for follow-up, research and informed consent", Reproductive biomedicine online, 34(5), 2017, pp. 480485.

VITA, Medicina reproductiva. Donantes de óvulos. Disponible en: http://www.vitafertilidad.com/donantes/ovulos (Consultado el 9 de mayo de 2019).

WALLACE, W.H.B. y KELSEY, T.W., "Human Ovarian Reserve from Conception to the Menopause", PLoS ONE 5(1): e8772, 2010. Disponible en: https://www.researchgate.net/publication/41174979 Human Ovarian Reserve fr om_Conception_to_the_Menopause (Consultado el 27 de julio de 2019).

WORLD HEALTH ORGANIZATION “WHO” (en español Organización Mundial de la Salud “OMS”), Infertility definitions and terminology. Disponible en: https://www.who.int/reproductivehealth/topics/infertility/definitions/en/

(Consultado el 10 de junio de 2019). 